Review Article

\title{
Drosophila: An Emergent Model for Delineating Interactions between the Circadian Clock and Drugs of Abuse
}

\author{
Aliza K. De Nobrega and Lisa C. Lyons \\ Department of Biological Science, Program in Neuroscience, Florida State University, Tallahassee, FL 32306, USA \\ Correspondence should be addressed to Lisa C. Lyons; lyons@bio.fsu.edu
}

Received 16 May 2017; Accepted 13 August 2017; Published 17 December 2017

Academic Editor: Harry Pantazopoulos

Copyright @ 2017 Aliza K. De Nobrega and Lisa C. Lyons. This is an open access article distributed under the Creative Commons Attribution License, which permits unrestricted use, distribution, and reproduction in any medium, provided the original work is properly cited.

\begin{abstract}
Endogenous circadian oscillators orchestrate rhythms at the cellular, physiological, and behavioral levels across species to coordinate activity, for example, sleep/wake cycles, metabolism, and learning and memory, with predictable environmental cycles. The 21 st century has seen a dramatic rise in the incidence of circadian and sleep disorders with globalization, technological advances, and the use of personal electronics. The circadian clock modulates alcohol- and drug-induced behaviors with circadian misalignment contributing to increased substance use and abuse. Invertebrate models, such as Drosophila melanogaster, have proven invaluable for the identification of genetic and molecular mechanisms underlying highly conserved processes including the circadian clock, drug tolerance, and reward systems. In this review, we highlight the contributions of Drosophila as a model system for understanding the bidirectional interactions between the circadian system and the drugs of abuse, alcohol and cocaine, and illustrate the highly conserved nature of these interactions between Drosophila and mammalian systems. Research in Drosophila provides mechanistic insights into the corresponding behaviors in higher organisms and can be used as a guide for targeted inquiries in mammals.
\end{abstract}

\section{Introduction}

1.1. Alcohol and Drug Abuse. The long-term chronic abuse of alcohol and other drugs has adverse consequences for individual health, society, and the economy [1-3]. Alcohol is one of the most commonly used and abused drugs in the United States [4] and the world [5]. As of 2014, 17 million Americans have an alcohol use disorder (AUD) representing $79 \%$ of the people diagnosed with substance use disorders, and additional 2.6 million (12.1\%) have comorbid AUD and illicit drug use disorder [4]. Alcohol and other drugs of abuse collectively account for $\sim 75,000$ deaths annually in the US $[6,7]$. In the United States, the health and economic costs associated with alcohol abuse are estimated at approximately $\$ 223$ billion annually [1] with costs associated with other drugs of abuse including tobacco, illicit drugs, and prescription opioids collectively estimated at approximately $\$ 571.6$ billion annually [8-10]. In the past few years, cocaine use has reemerged as a public health problem with a $26 \%$ increase in the number of new users in 2015 compared to
2014, with the greatest increase in users occurring among young adults [11]. Understanding the factors that contribute to alcohol and substance abuse and addiction and drug pathologies is critical for the development of therapies for the prevention and treatment of substance abuse disorders.

1.2. The Link between the Circadian Clock and Drug Use. From bacteria to humans, circadian clocks regulate cellular, physiological, and behavioral rhythms in coordination with the natural light-dark cycle (Figure 1). In addition to light, entrainment of the peripheral circadian system can be mediated by food intake schedules, exercise, or social activity [12-14]. The circadian clock modulates rhythms in metabolism, gene expression, hormone production, cell regeneration, and brain wave activity [15-17]. In the past two decades, the importance of the circadian clock in modulating alcohol and drug use and the associated pathologies has become more apparent (Figure 2). Individuals with an evening chronotype, the behavioral pattern reflecting an individual's circadian phase, exhibit higher levels of alcohol 


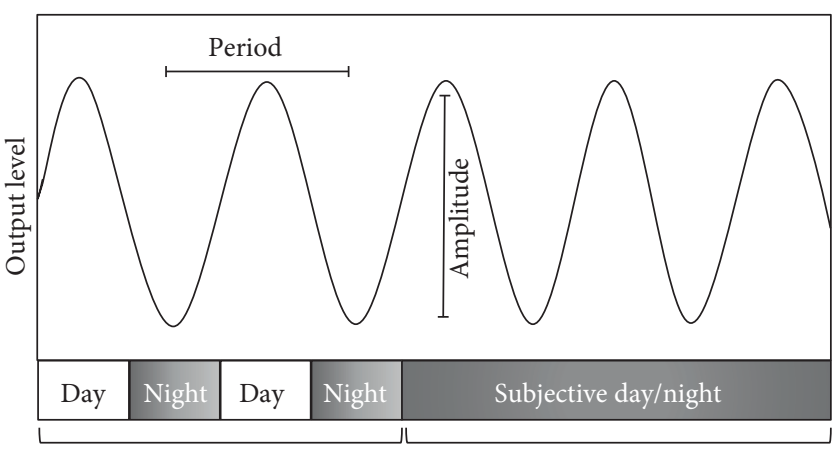

LD-entrained rhythm

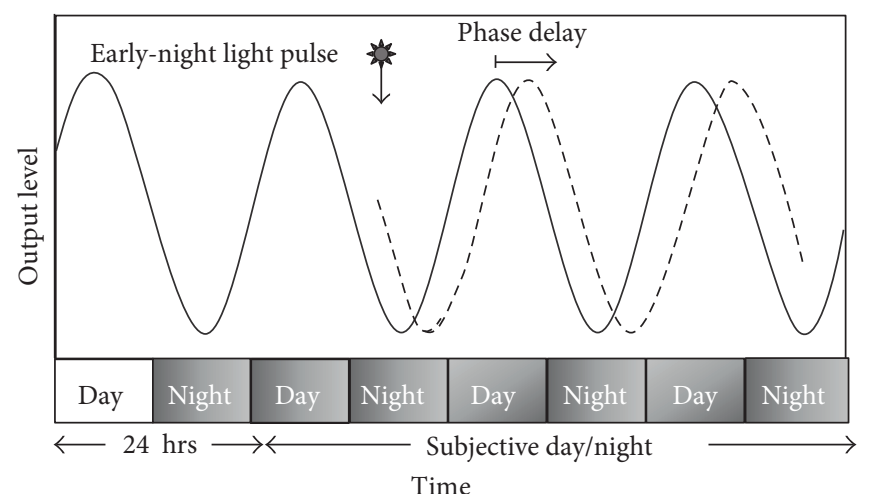

(b)

(a)

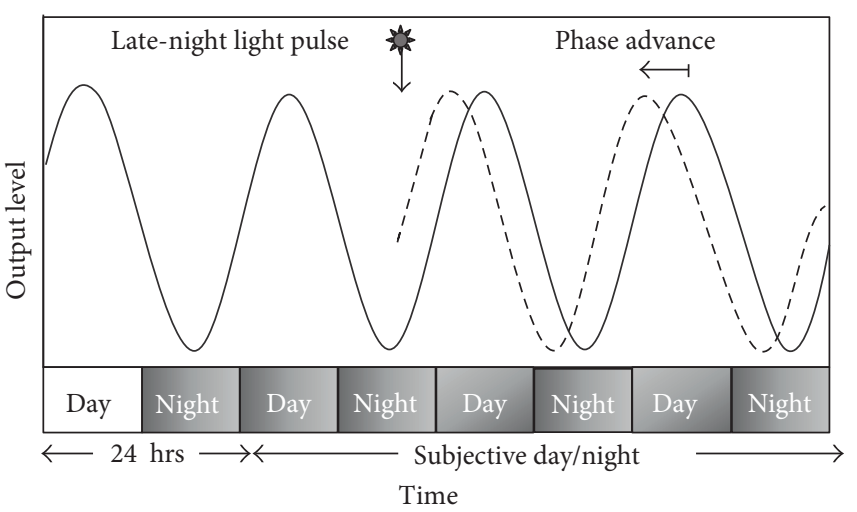

(c)

FIGURE 1: Measures of the circadian rhythm. (a) Cycles of peaks and troughs of activity occur at approximately 24-hour intervals. The period of the cycle is the time between successive peaks (or troughs) of activity whereas the extent of the increase or decrease in activity represents the amplitude of the cycle. (b) An early-night light pulse results in a phase delay. (c) A late-night light pulse results in a phase advance.

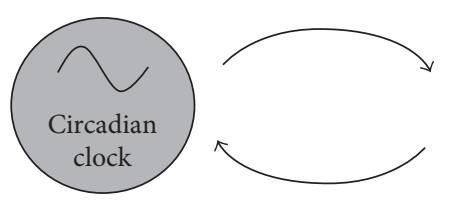

(a)

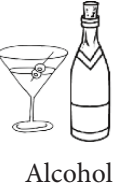

Alcohol

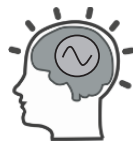

Master circadian clock

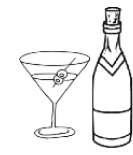

Alcohol sensitivity

(b)

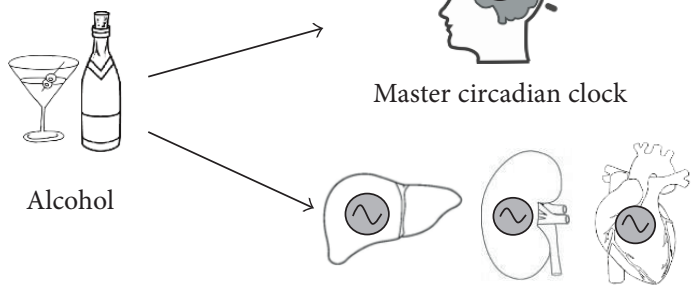

Peripheral oscillators

(c)

Figure 2: The bidirectional relationship between the circadian clock and alcohol. (a) The circadian clock modulates alcohol sensitivity and alcohol consumption. Alcohol acts upon circadian oscillators to affect phase shifting of oscillators as well as expression patterns of circadian genes leading to circadian dysfunction. (b) The master circadian clock in the brain modulates the behavioral sensitivity to alcohol including hyperactivity, sedation, recovery, and tolerance. (c) Alcohol affects the master circadian clock in the SCN as well as in peripheral oscillators in the liver, kidney, and heart. 


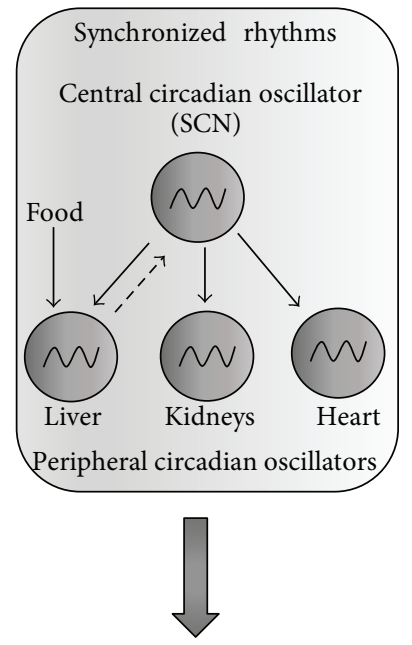

Normal physiology

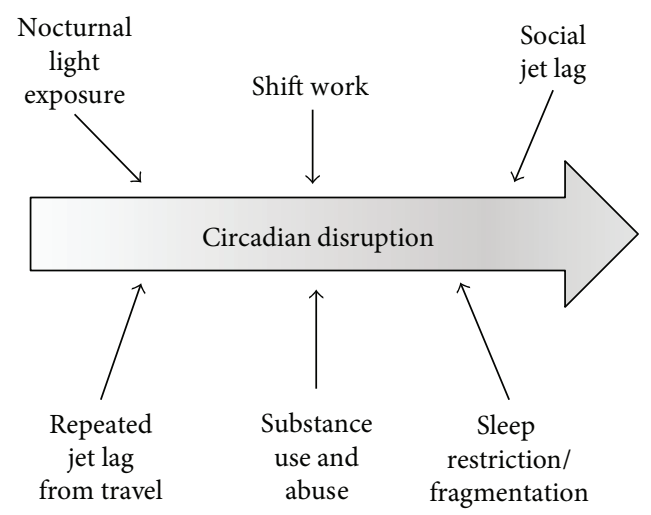

Metabolic dysfunction and disease

FIGURE 3: Central and peripheral circadian regulation of metabolic function. Under normal conditions, the central circadian oscillator in the $\mathrm{SCN}$ is entrained by light and synchronizes peripheral oscillators. Meal timing can also entrain the liver oscillators. Environmental perturbations such as shift work, jet lag, sleep restriction, and substance abuse create misalignment between the SCN and the peripheral oscillators resulting in metabolic syndromes and disease.

use $[18,19]$ and increased drug use [20, 21]. Recent research using functional imaging has shown that evening chronotypes have altered neural responses to reward compared to morning chronotypes with increased activity in the ventral striatum and decreased reactivity in the medial prefrontal cortex [22] which has previously been associated with increased alcohol consumption [23].

1.3. Circadian Misalignment. Impairments of the circadian system or desynchronization adversely affects individual health with increased risk of obesity, diabetes, cardiovascular diseases, cancer, and mood disorders [24-28] (Figure 3). Recently, research in animal models and humans has linked circadian dysfunction with increased risk of drug and alcohol abuse. Drug abuse and drug-related pathologies appear higher in populations in which circadian misalignment and sleep deprivation are common $[3,29]$ including shift workers [30-32] and aging individuals [33]. These substance abuse issues are expected to escalate with increases in the aging population and the proportion of people working extended and rotating shifts [34-36]. Drug abuse and alcohol abuse affect the functioning of the circadian system with the subsequent circadian dysfunction increasing the risks and harms of drug abuse. In this review, we will discuss factors contributing to the increase in sleep and circadian disorders and focus on Drosophila as a model for investigating the bidirectional interactions between the circadian clock and drug use.

\section{Factors Contributing to the Increase in Circadian and Sleep Disorders}

2.1. Work Schedules. In the past few decades, the number of individuals affected by circadian or sleep disorders has rapidly risen [37]. Insufficient sleep is a pervasive problem affecting approximately $30 \%$ of adults and $60 \%$ of adolescents [38]. Technological advances and globalization have driven changes in occupational and professional practices with a greater number of individuals working extended hours and shift work. In the United States and other developed countries, approximately $15-30 \%$ of the population work irregular or shift work schedules $[36,38]$ contributing to increased circadian and sleep disorders. Individuals working longer days and extended work weeks have become increasingly more common with more than $18 \%$ of the people in the United States working more than 48 hours per week [36]. These problems are compounded by poor entrainment of the circadian clock in modern societies.

2.2. Circadian Entrainment and Artificial Light at Night. The circadian system and sleep profiles evolved in coordination with the natural light-dark cycles with light providing the strongest zeitgeber or entrainment signal to the circadian oscillator. With the majority of the world's population now living in urban environments [39], artificial indoor lighting substitutes for the natural light-dark cycle entrainment of the circadian clock. Studies in the United States, Canada, and England found that individuals spend less than $12 \%$ of their time outside or less than 1-2 hours per day overall [40-43]. As indoor light levels (100-300 lux) are orders of magnitude lower than those of direct sunlight (10,000 lux range), decreased time outdoors results in weaker signals to the circadian clock and poorer entrainment [44]. In contrast to light signals during the day, light at night shifts the phase of the circadian clock (Figures 1(b) and 1(c)). It has been estimated that $99 \%$ of individuals living in the United States and Europe and $80 \%$ of the people worldwide experience 
significant light pollution at night $[45,46]$. During the night, light from a full moon is less than 1.0 lux of light, usually 0.10.3 lux [45]. However, artificial light at night is considerably higher from a variety of sources including outdoor lighting estimated at 5-15-lux light exposure, indoor evening lighting at 100-200-lux light exposure, and personal electronic use ranging up to 100-lux light exposure [45]. In the past decade, the shift from the use of incandescent light bulbs to the use of fluorescent and LED lights with shorter wavelengths increases the potential for circadian disruption at night as melanopsin, the circadian photopigment, is particularly sensitive to shorter-wavelength blue light $[47,48]$. Increased exposure to artificial light at night has been associated with increased risk of cancer, diabetes, obesity, and mood and behavioral disorders [45, 49-51]. Increased artificial light at night $[46,52]$ combined with reduced individual exposure to daytime sunlight [43] contributes to weakened circadian entrainment and circadian dysfunction. Poor entrainment and low-level circadian function make it more difficult to maintain synchronization of central and peripheral circadian clocks in the face of circadian perturbation.

2.3. Evening Chronotype. An individual's chronotype may also increase the risk of circadian desynchronization. Individuals with evening chronotypes are prone to even greater late-night phenotypes with less exposure to sunlight and more reliance on artificial lighting compounding the problem [53]. The phase of the circadian clock changes with development and aging. Whereas young children have a morning chronotype, in teenagers and young adults, the biological clock is naturally shifted by several hours resulting in the prevalence of evening chronotypes in this age group [54-56]. Fixed work and school schedules compound the problem of circadian dysfunction in individuals with an evening chronotype.

2.4. Personal Electronics. The use of personal electronics and shifts in activity patterns between weekdays and weekends strongly contribute to the rise in circadian and sleep disorders. The use of smartphones and personal electronics at night has further potentiated circadian disorders and associated problems by increasing exposure to light during the night $[45,57,58]$. Computer and cell phone use at night by adolescents has been correlated with decreased weekday sleep [59]. Teenagers and young adults are particularly susceptible to smartphone dependence [60], with more than $50 \%$ of adults and approximately $75 \%$ of children and adolescents exhibiting signs of dependence upon their smartphones including anxiety [61]. Smartphone dependence appears almost universal around the world contributing to sleep disorders and poor sleep quality in teenagers, college students, and adults $[62,63]$.

2.5. Social Jet Lag. Social jet lag, defined as a change in activity/rest patterns between workdays and free days, results in individuals continuously undergoing shifts to their circadian clock and a perpetual state of circadian misalignment as peripheral circadian oscillators have insufficient time to resynchronize prior to the next phase shift (Figure 3). Social jet lag is prevalent in adults and adolescents, particularly in individuals with an evening chronotype, with estimates of social jet lag affecting almost $70 \%$ of individuals [64]. Social jet lag has been correlated with increased obesity [65], diabetes, cardiac function and heart disease [66, 67], and depression [68]. Higher levels of alcohol use observed in individuals with evening chronotypes may be compounded by social jet lag [18].

\section{Drosophila as a Versatile Model System}

3.1. Advantages of Drosophila. Drosophila is an excellent model system for dissecting the bidirectional connections between the circadian clock and drugs of abuse as the signaling pathways that regulate reward processes, addiction, and circadian function are highly conserved between Drosophila and mammals [69-71]. The free-running period in Drosophila is approximately 24 hours with flies exhibiting crepuscular activity under laboratory conditions including dawn anticipatory activity $[72,73]$. The relatively short life cycle, the ability to generate large populations in a short time period, and the low cost of culture and maintenance in Drosophila permit complex genetic experiments to be completed in a fraction of the time it would take in vertebrate models $[74,75]$. Powerful neurogenetic techniques including forward genetic screens, reverse genetic techniques with genome-wide RNAi lines available, and optogenetic monitoring to assess individual neuronal changes using voltage or calcium sensors have enhanced the utility of the Drosophila model [76-81]. Drosophila also provides an excellent model to study the complexity of the aging process, offering the ability to characterize single-gene mutations that extend or shorten lifespan [82-85]. Similar to mammals, Drosophila shows declines with aging in functional and behavioral performance including sensory functions [86, 87], circadian and sleep-like behavior [88-92], learning and memory [93-95], locomotion [96-98], and organ function [99-101].

3.2. Conservation between Drosophila and Mammals. The physiological mechanisms underlying most biological processes between Drosophila and mammals are remarkably well conserved despite the obvious differences in anatomical structure and complexity $[102,103]$. The fly genome contains approximately 14,000 genes, and it is estimated that nearly $75 \%$ of the genes implicated in human diseases have functional orthologs in the fly, with 80 to $90 \%$ similarity in conserved functional domains at the nucleotide level or protein sequence [104-106]. Anatomically, Drosophila has functional equivalents of the mammalian heart [107-109], lung $[110,111]$, kidney $[112,113]$, gut [114-116], and reproductive tract $[117,118]$.

Despite the considerable neuroanatomical differences between flies and mammals, the molecular, cellular, genetic, and electrophysiological properties underlying neuronal behavior and synaptic plasticity also are well conserved $[119,120]$. The approximately 100,000 neurons constituting the fly brain form discreet networks that regulate complex behaviors such as sleep [121-123], learning and memory $[124,125]$, grooming and feeding $[69,126-129]$, circadian 
rhythms [130-134], aggression [135, 136], and courtship $[137,138]$. The fundamental mechanisms comprising the homeostatic systems and neurochemical circuits are also conserved between Drosophila and mammals $[69,139,140]$. At the molecular level, neurotransmission also appears highly conserved from Drosophila to mammalian species with classical neurotransmitters including acetylcholine, GABA, glutamate, dopamine, octopamine, serotonin, histamine, and peptide neurotransmitters such as neuropeptide Y/neuropeptide $\mathrm{F}$ and insulin-like peptides common to both $[69,141,142]$.

The striking mechanistic similarities to mammals have propelled Drosophila to the forefront as a competitive model to investigate the link between the circadian system and drug sensitivity, abuse, and addiction. In this review, we highlight Drosophila research revealing the interactions between the circadian clock and two drugs of abuse, alcohol and cocaine, and the parallels to mammalian systems.

\section{Drosophila as a Model for the Circadian Clock}

Since the 1950s and the pioneering work of Colin Pittendrigh, Drosophila has been a prominent model for research defining the conceptual, functional, and molecular basis of the circadian clock [143-147]. The circadian clock in Drosophila modulates a broad spectrum of physiological and behavioral processes including locomotor activity, sleep patterns, courtship, learning and memory, feeding behavior, chemosensation, and immune responses [148-157]. As in mammals, the Drosophila circadian oscillators also coordinate rhythms in peripheral organs, such as olfactory and gustatory sensitivity rhythms [158-160] and the mitotic response of gut stem cells to damage [161].

Konopka and Benzer isolated the first clock gene mutants in 1971 using forward genetics in Drosophila and analysis of the period length of the circadian rhythm in eclosion [162]. Flies with mutations in the gene period (per ${ }^{L}, \mathrm{per}^{S}$, and $p^{01}{ }^{01}$ ) exhibit rhythms in eclosion that are longer, shorter, or arrhythmic, respectively [162]. Identification of per spawned additional genetic screens for components of the circadian clock leading to the discovery of timeless, clock, cycle, doubletime, shaggy, casein kinase 2 subunits, and cryptochrome [163-172]. These studies and subsequent identification of the corresponding genes facilitated research in mammalian systems leading to the discovery of mammalian per and clock genes, the first circadian genes identified and sequenced in mice [173-175].

The Drosophila central brain circadian system comprises approximately 150 clock neurons organized into a network of oscillators: the small and large ventral lateral neurons which control the morning peak of activity and the lateral dorsal and dorsal neurons that control the evening peak of activity [176, 177]. Circadian rhythms generated by both the Drosophila and mammalian clock are driven by interlocking autoregulatory transcriptional/translational feedback loops along with posttranscriptional regulatory elements that facilitate the rhythmicity of the clock and generate the 24 -hour period [176, 178-183]. Figure 4 provides an overview of the molecular clock in Drosophila and mammals. As additional information on the molecular mechanisms of the core circadian oscillators in Drosophila and mammals is provided in many excellent reviews [176, 184-186], we only briefly describe the core clock mechanism below.

In Drosophila, the positive regulatory elements in the core oscillator are the basic-helix-loop-helix transcriptional elements clock (clk) and cycle (cyc) which form a heterodimer and bind to the per and timeless (tim) DNA promoters to activate transcription of the core circadian genes, per and tim $[166,167,171]$, and hundreds of clock-controlled output genes $[187,188]$. Monomers of the PER protein are unstable, phosphorylated by doubletime (DBT), and targeted for degradation. As dTIM and dPER levels rise, they form a dTIM/dPER/DBT complex which translocates to the nucleus and binds to the dCLK/dCYC complex [165, 172, 189], thereby inhibiting transcription of the per and tim genes $[182,189]$. In mammals, the positive regulatory elements are the transcriptional elements CLOCK (CLK) and BMAL1 (instead of CYC) which form a heterodimer to activate transcription of the clock genes: three orthologs of period (mPer1, $\mathrm{mPer} 2$, and $\mathrm{mPer} 3$ ) and two cryptochrome genes ( $\mathrm{mCry} 1$ and $\mathrm{mCry} 2$ ) as well as other clock-controlled genes $[190,191]$. Following translation of the proteins mPER and mCRY, the proteins dimerize to mediate stability and nuclear translocation and then interact with the mCLK/ mBMAL1 complex in the nucleus, inhibiting further transcriptional activation [191]. In flies as in mammals, posttranscriptional elements are necessary for the regulation of protein stability, nuclear entry, and fine-tuning of period length $[170,189,192]$. These include the kinases doubletime (DBT), the homolog to mammalian casein kinase 1 epsilon (CK1E) [172] which targets dPER for phosphorylation and subsequent degradation [165], and dSHAGGY, a homolog to the mammalian glycogen synthase kinase-3 (mGSK3) [193] which aids in nuclear translocation of the dTIM/dPER/dDBT complex $[170,189,192]$. The above provides a brief outline of the core circadian oscillator with more detailed descriptions of the circadian oscillator and its components in Drosophila and mammalian models available in several recent review articles [176, 180, 189, 194].

\section{Drosophila as a Model for Studies of Alcohol Neurobiology}

5.1. Alcohol-Induced Behaviors. As a model system, Drosophila has exemplified the value of invertebrate research and its parallels and conversion into meaningful knowledge in mammalian systems particularly for studies of drugs of abuse $[139,195,196]$. See Table 1 for comparisons of druginduced behaviors and assays used in Drosophila and rodent models. Stereotypical behaviors associated with alcohol exposure are conserved between flies, rodents, and humans $[74,139,197]$ including hyperactivity in response to low concentrations of alcohol followed by loss of motor control as alcohol exposure progresses [139, 198-200]. Prolonged exposure to alcohol results in the development of functional tolerance, sedation, and eventually death [139, 198-200]. Similar to mammalian species, Drosophila also exhibits sex 


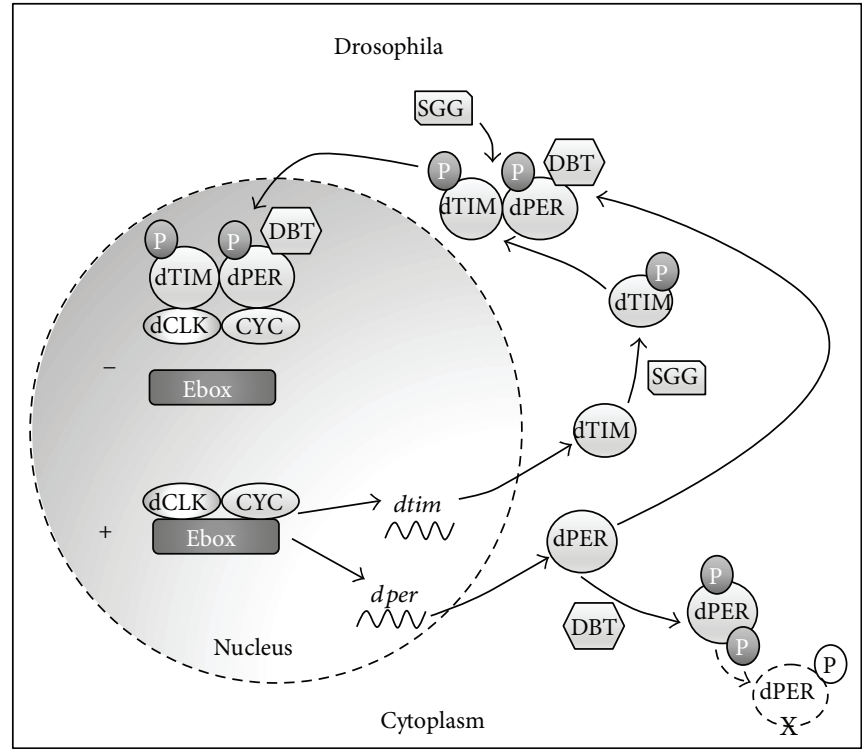

(a)

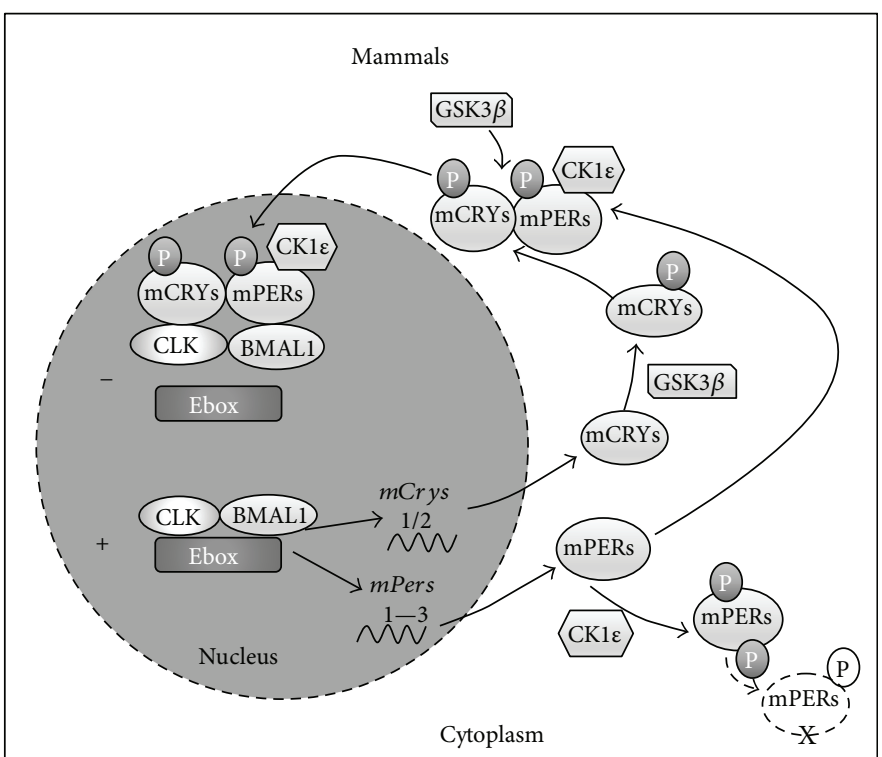

(b)

Figure 4: The molecular clocks of Drosophila (a) and mammals (b). (a) In Drosophila, dCLK and CYC form a dimer, which binds to the E boxes in the promoter of per and tim as well as to other clock-controlled genes to facilitate transcription. PER and TIM proteins form a complex and translocate into the nucleus providing negative feedback to inhibit dCLK-CYC DNA binding. Phosphorylation mediated by DBT and SGG regulates protein-protein interactions, nuclear translocation, and degradation. (b) In mammals, the transcription factors BMAL1 and CLK form a dimer that binds to E boxes in the promoter of $m$ Per and $m C r y$. mPER and mCRY proteins form dimers, enter the nucleus, and inhibit the BMAL1-CLK activity. Phosphorylation mediated by CK1 and GSK3 regulates protein-protein interactions, nuclear translocation, and degradation.

differences in alcohol sensitivity with males less sensitive to the acute behavioral effects of alcohol but more susceptible to alcohol-induced mortality than females [201, 202].

The molecular and neural mechanisms underlying alcohol-induced behavioral changes appear conserved between flies and mammals [69, 198, 199, 203] making Drosophila a practical model for studying the development of functional tolerance, addiction, and reward pathways. Functional tolerance includes the development of rapid and chronic tolerance due to changes in neuronal plasticity rather than changes in the absorbance and metabolism of alcohol [204-206]. Like higher vertebrates, flies develop rapid tolerance following a single alcohol exposure and chronic tolerance with multiple or prolonged alcohol exposure [71, 139, 200]. Drosophila demonstrates a preference for alcohol-containing food over non-alcohol-containing food [198, 207-209], although the question has arisen as to whether the underlying preference is due to its caloric value [210]. Recent research has shown that the preference for and voluntary consumption of alcohol in Drosophila are 
TABle 1: Behavioral measures and assays of drug addiction in Drosophila and rodents.

\begin{tabular}{|c|c|c|c|}
\hline \multirow{2}{*}{ Behavior } & \multirow{2}{*}{ Assay } & \multicolumn{2}{|c|}{ Examples of research studies } \\
\hline & & Drosophila & Rodents \\
\hline $\begin{array}{l}\text { Reward/preference } \\
\text { Induced state that leads to conditioned reinforced } \\
\text { behavior }\end{array}$ & $\begin{array}{l}\text { (1) Self-administration } \\
\text { (2) Electrical stimulation } \\
\text { (3) Conditioned place preference } \\
\text { (4) Conditioned taste preference } \\
\text { (5) Conditioned taste avoidance }\end{array}$ & $\begin{array}{l}\text { (1) }[198,207,211] \\
\text { (2) }[200] \\
\text { (3) }[198,200] \\
\text { (4) }[198,398] \\
\text { (5) }[198]\end{array}$ & $\begin{array}{l}\text { (1) }[399] \\
\text { (2) }[400,401] \\
(3)[402,403] \\
\text { (4) }[399,404] \\
\text { (5) }[405,406]\end{array}$ \\
\hline $\begin{array}{l}\text { Drug seeking } \\
\text { Affective state inferred from increased behavioral } \\
\text { responses to drugs, drug-associated cues, or stress }\end{array}$ & $\begin{array}{l}\text { (1) Self-administration } \\
\text { (2) Electrical stimulation }\end{array}$ & $\begin{array}{l}(1)[198] \\
(2)[200]\end{array}$ & $\begin{array}{l}\text { (1) }[407,408] \\
\text { (2) }[409,410]\end{array}$ \\
\hline $\begin{array}{l}\text { Functional tolerance } \\
\text { Adaptations in neural function } \\
\text { Rapid tolerance } \\
\text { Following a single acute exposure when drug has } \\
\text { metabolized } \\
\text { Chronic tolerance } \\
\text { Following prolonged or repeated drug exposures }\end{array}$ & $\begin{array}{l}\text { (1) Injection behavioral assays } \\
\text { (2) Self-administration } \\
\text { (3) Sedation and negative geotaxis } \\
\text { assay }\end{array}$ & $\begin{array}{l}\text { (1) }[228] \\
(2)- \\
\text { (3) }[204,205,280]\end{array}$ & $\begin{array}{l}\text { (1) }[405,411] \\
\text { (2) }[412] \\
\text { (3) }[413,414]\end{array}$ \\
\hline $\begin{array}{l}\text { Sensitization } \\
\text { Increased motor-stimulant response following repeated } \\
\text { drug exposures }\end{array}$ & (1) Locomotor activity test & (1) $[332,334,415,416]$ & (1) $[324,417-420]$ \\
\hline $\begin{array}{l}\text { Withdrawal } \\
\text { Aversive state that motivates drug seeking }\end{array}$ & $\begin{array}{l}\text { (1) Conditioned place aversion } \\
\text { (2) Sedation and negative geotaxis } \\
\text { (3) Self-administration }\end{array}$ & $\begin{array}{l}(1)- \\
(2)[421,422] \\
(3)-\end{array}$ & $\begin{array}{l}\text { (1) }[423] \\
(2)[424,425] \\
\text { (3) }[426,427]\end{array}$ \\
\hline $\begin{array}{l}\text { Relapse/reinstatement } \\
\text { Spontaneous recovery of drug seeking after abstinence } \\
\text { or extinction of behavior may be triggered by } \\
\text { cues previously paired with drug use or stress }\end{array}$ & $\begin{array}{l}\text { (1) Self-administration } \\
\text { (2) Electrical stimulation } \\
\text { (3) Injections }\end{array}$ & $\begin{array}{l}(1)[198,428] \\
(2)- \\
(3)-\end{array}$ & $\begin{array}{l}\text { (1) }[429,430] \\
\text { (2) }[431,432] \\
\text { (3) }[433]\end{array}$ \\
\hline
\end{tabular}

experience-dependent based upon previous alcohol exposure [211] and independent of caloric, gustatory, or olfactory biases for alcohol [209]. Drosophila also exhibits alcohol addiction-like behavior preferring alcohol-containing food even when accompanied by a noxious stimulus as well as relapse-like behavior with high levels of alcohol consumption after alcohol deprivation [198, 208].

5.2. Molecular Pathways in Alcohol Responses. The power of genetic approaches in Drosophila has facilitated the identification of molecular and cellular mechanisms that mediate alcohol-induced behavior and neural plasticity $[212,213]$ with many of the identified genes and molecular pathways playing a similar role in mammalian responses to alcohol $[214,215]$.

5.2.1. cAMP-PKA Pathway. Mutagenesis studies in flies have provided substantial evidence for the role of the cAMPprotein kinase A pathway in alcohol-induced behavioral responses including the adenylyl cyclase-encoding gene, rutabaga; the cAMP phosphodiesterase-encoding gene, dunce; and the PKA-C1-encoding gene, dco [216]. Increased sensitivity to alcohol-induced sedation is observed in rutabaga flies although dunce mutant flies exhibit sensitivity to alcohol-induced sedation similar to wild-type flies [216]. Flies with mutations in PKA show altered alcohol sensitivity with mutations in the catalytic subunit (dco mutation) making them more sensitive to the sedating effects of alcohol
[216] while flies with a mutation in the RII subunit of PKA exhibit reduced sensitivity to alcohol-induced sedation [217]. The preference for alcohol self-administration and potentially the processing of its reward salience are also dependent upon adenylyl cyclase activity [209]. The role of cAMP-PKA signaling in alcohol neurobiology appears conserved across species. Genetic downregulation of the cAMP-PKA pathway in mice through manipulation of $G$ protein transduction increases sensitivity to ethanol while upregulation of adenylyl cyclase activity reduces the sensitivity of mice to alcohol-induced sedation [218]. Mice with a knockout mutation in the RII $\beta$ subunit of PKA exhibit lowered alcohol sensitivity [219] similar to what is observed in flies. The PACAP-like analog amnesiac encodes a putative neuropeptide which may trigger the cAMP-PKA pathway via adenylate cyclase activity [220]. Flies with mutations in the amnesiac gene also exhibit increased sensitivity to the sedative effects of alcohol [216]. Thus, the cAMP-PKA pathway appears to be a key regulator in behavioral alcohol sensitivity and the preference for alcohol across species.

5.2.2. The LMO-ALK Axis. Drosophila LIM-domain only $(d L m o)$, also known as Beadex, encodes a transcriptional regulator that affects behavioral responses in the adult fly to alcohol and cocaine. In flies, decreased $d L m o$ levels increase alcohol sensitivity with flies sedating more quickly while increased $d L m o$ decreases sensitivity to alcohol sedation [221]. Similarly, mice with reduced expression of Lmo3 
exhibit increased sensitivity to the sedating effect of alcohol [221, 222]. Lmo3-null mice also drink more alcohol in the "drinking in the dark" test compared to wild-type mice [222]. In a microarray analysis for gene targets with inverse expression of the $B x$ repressor, the Drosophila homolog of anaplastic lymphoma kinase (dAlk) was found to be negatively regulated by $d L m o$ [221]. Flies with mutations in dAlk show increased resistance to alcohol-induced sedation [223]. $d A l k$ has been shown to modulate Erk activity in the fly brain and likely influences sensitivity to alcohol via Erk signaling [224]. Similarly, rodent and human orthologs of $d A l k$ include $B x$ (Lmo4) and Alk that have been shown to modulate alcohol sensitivity and consumption and may be involved in alcohol dependence [223, 225-227]. Alk-knockout mice also show higher alcohol consumption compared to wildtype mice [223].

5.2.3. GABA Neurotransmission. The effects of alcohol on neurotransmission, particularly on glutamate and GABA neurotransmission, are also conserved across species [69, $71,215]$. Alcohol affects GABA neurotransmission through binding to $\mathrm{GABA}_{\mathrm{A}}$ and $\mathrm{GABA}_{\mathrm{B}}$ receptors [215]. In Drosophila, $\mathrm{GABA}_{\mathrm{B}}$ receptor activity mediates alcohol sensitivity and upregulation inhibits rapid tolerance to alcohol exposure [228]. Flies with $\mathrm{GABA}_{\mathrm{B}} \mathrm{R} 1$ downregulation through RNAi expression have decreased $\mathrm{GABA}_{\mathrm{B}}$ receptor function and exhibit decreased alcohol-induced motor impairments [228]. Pharmacological downregulation of $\mathrm{GABA}_{\mathrm{B}}$ also decreases alcohol sensitivity whereas flies treated with a $\mathrm{GABA}_{\mathrm{B}}$ agonist (3-APMPA) fail to develop rapid alcohol tolerance [228]. Similarly in mice, the $\mathrm{GABA}_{\mathrm{B}}$ agonist baclofen blocks the development of rapid tolerance [229] and $\mathrm{GABA}_{\mathrm{B}}$ antagonists attenuate the acute sensitivity to alcohol [230]. However, the observed effect of baclofen on self-administration of alcohol has varied with some studies indicating that baclofen decreases voluntary alcohol consumption [231, 232] while others demonstrate increased alcohol consumption $[233,234]$. This confusion has recently been answered, at least in part, as enantiomer specificity was found to be a critical factor in the directionality of baclofen on alcohol consumption [235]. In alcoholic patients, baclofen has also been shown to reduce alcohol craving [236-240].

5.2.4. Glutamate Signaling. The protein Homer functions as an adaptor protein in the postsynaptic density coupling membrane proteins with downstream signaling, including glutamate receptors. Transcript levels of homer decrease in wild-type flies following alcohol exposure, and homer ${ }^{R 102}$ mutant flies demonstrate increased sensitivity and decreased tolerance to alcohol exposure [241]. Homer2-KO mice demonstrate reduced voluntary drinking, reduced preference for alcohol, and increased sensitivity to alcohol confirming a conserved role of Homer function in the regulation of alcohol-induced behaviors [242]. More recently, chronic alcohol exposure has been shown to increase Homer $2 a / b$ and $m G l u R 1$ expression in the nucleus accumbens core $(\mathrm{NaCc})$ and central amygdala $(\mathrm{CeA})$ of rats reinforcing previous research that chronic alcohol induces glutamatergic plasticity in the brain $[243,244]$.
5.2.5. Potassium Channels. Further evidence for the high degree of conservation in alcohol tolerance arises from the studies of the gene slowpoke (slo) that encodes the Big Potassium (BK) channel-forming subunits. SLO is necessary for the acquisition of rapid tolerance with reduced slo expression in flies eliminating the ability to acquire tolerance [245-247]. Increasing slo expression in the Drosophila brain mimics functional alcohol tolerance [245, 248]. Mammalian BK channels encoded by slo are inhibited and potentiated by alcohol [249-251]. Stimulation of BK channels in the rat supraoptic nucleus and striatum increases the response to alcohol-induced tolerance [252]. The actions of alcohol on BK channels are dependent upon the ?1-?4 subunits shown to reduce the potentiation of $\mathrm{BK}$ channels following acute alcohol exposure [250, 253-255].

5.2.6. Reward Signaling: Dopamine and NPY. Reward pathways mediating alcohol addiction and abuse are also conserved between flies and mammals $[69,139]$. Dopamine is a pleiotropic modulator of behavior strongly implicated in the development of reward and addiction in mammals and flies [256-260]. In flies, dopamine signaling via $\mathrm{D}_{1}$ receptors is necessary for alcohol-induced hyperactivity and preference [200, 257, 261] with dopaminergic neurons in the ellipsoid body of the central complex critical for the regulation of alcohol-induced hyperactivity [257]. Similarly, fast and steep increases in dopamine activate low-affinity $\mathrm{D}_{1}$ dopamine receptors necessary for the rewarding effects of alcohol and triggering alcohol-induced conditioned responses in mammals [262].

Another neuropeptide, neuropeptide Y (NPY), plays a prominent role in the negative affective behaviors associated with stress and alcohol $[263,264]$ with a conserved role in reward pathways across species. In mammalian studies, rats selectively bred for high alcohol preferences have low levels of NPY expression in the striatum and increased anxietylike behaviors [265]. Mice selected for high alcohol preference also show blunted NPY in the nucleus accumbens core and shell in response to acute alcohol exposure compared to control mice [266]. Manipulations of NPF signaling, the Drosophila homolog of NPY, affect alcohol preference with inhibition of the NPF pathway enhancing alcohol preference while NPF activation reduces alcohol preference [267]. Flies with loss-of-function mutations in NPF/NPFR1 signaling also exhibit decreased sensitivity to alcohol sedation whereas flies in which NPF is overexpressed show increased sensitivity to alcohol sedation [268].

5.2.7. Cellular Stress Pathways. Genes involved in cellular stress responses may also have a conserved role in the development of alcohol tolerance including heat shock proteins, cytochrome $\mathrm{P} 450$ proteins, and glutathione transferases [269]. The hangover gene is a Zn-finger transcription factor necessary for cellular oxidative stress responses [270]. Flies with a mutation in hangover exhibit decreased rapid alcohol tolerance, although no differences are observed in alcoholinduced sedation [247]. The human ortholog of hangover is ZNF699, and human studies have identified polymorphisms in this gene associated with alcohol dependence [271, 272]. 
Another stress-related gene involved in alcohol tolerance is the microtubule-associated protein jwa (alias ARL6IP5, addicsin), which increases in response to oxidative stress and heat shock in mammals [273, 274]. In flies, RNAimediated knockdown of djwa decreases the development of alcohol tolerance [275]. In mammals, the homologous addicsin has been implicated in the development of morphine tolerance [276]. While considerably more research needs to be done, there appears to be a conserved role for proteins involved in cellular stress responses in alcohol and drug tolerance across species.

5.2.8. Regulation of Cytoskeletal Elements. Regulation of actin dynamics also has been implicated in alcohol-induced behavioral responses. The Rho family of GTPases, including Rho1, Rac1, and Cdc42, regulates actin dynamics. In flies, Ras suppressor1 (Rsu1) regulates alcohol sensitivity functioning through the regulation of actin dynamics upstream of Rac1 GTPase [277]. Flies with mutations in Rsul exhibit reduced sensitivity to alcohol and a naïve preference for higher alcohol consumption that remains unchanged with experience [277]. Furthermore, the Rho GTPase activator protein 18B (RhoGAP18B) with three protein isoforms affect actin dynamics of which the RhoGAP18B PC isoform also affects the sensitivity to alcohol-induced sedation and hyperactivity [278, 279]. The loss of the full-length RhoGAP18B PC protein decreases alcohol sensitivity [278, 280]. Human genome-wide association studies have found correlations between Rsu1 SNP and ventral striatum activity, and a mutation in Rsul is associated with alcohol dependence [277]. Further, activation of the Arf6 small GTPase results in increased resistance to alcohol-induced sedation, and flies with reduced expression are more sensitive to alcohol [281, 282]. The Efa6 activation of Arf6 is required for normal responses to alcohol-induced sedation as Arf6 and Efa6 mutant flies show reduced sensitivity to alcohol-induced sedation and no rapid tolerance to alcohol exposure [283]. Human genome-wide association studies show correlations between SNPs of Arf6 and Efa6 and increased alcohol drinking behavior [283].

The strikingly similar molecular and cellular mechanisms underlying alcohol-responsive behaviors in flies and mammals validate Drosophila as a model for alcohol research. Although obvious neuroanatomical differences exist between mammals and flies, alcohol affects brain regions in flies for which functionally similar parallels can be drawn to specific mammalian brain regions [139, 199]. The brain regions involved in Drosophila alcohol neurobiology and detailed description of genes and molecular pathways have been the subject of several recent reviews [71, 139, 199, 200, 284].

\section{Drosophila Links Circadian and Alcohol Neurobiology}

The interaction between time of day and the sensitivity to alcohol was described more than a half-century ago with studies in mice detailing time-of-day differences in alcohol toxicity [285]. Since that time, numerous behavioral studies have documented the circadian regulation of alcohol sensitivity and the bidirectional influence of alcohol on the functioning of the circadian clock [286-289]. The emergence of Drosophila as a model for alcohol research has expanded the opportunities for defining the bidirectional interactions between alcohol and the circadian clock using behavioral and genetic studies.

6.1. Circadian Regulation of Alcohol Behavioral Sensitivity. As the neural circuitry and molecular signaling pathways may differ between alcohol-induced behaviors, the potential for circadian regulation of multiple behaviors has been examined in Drosophila including the loss of righting reflex which reflects the loss of postural motor control after alcohol exposure, alcohol-induced sedation, the recovery from sedation, and functional tolerance. In Drosophila, the circadian clock differentially regulates acute behavioral sensitivity to alcohol dependent upon time of day with circadian rhythms in alcohol-induced loss of righting reflex and sedation occurring in both light-dark cycles and constant darkness [202, 290]. Flies exhibit the greatest sensitivity to alcohol during the mid-to-late subjective night in correspondence to the flies' inactive phase $[202,290]$. The time to recover from the sedative effects of alcohol is also significantly greater at night [202]. Phase-dependent correlation of alcohol sensitivity with activity may be a conserved feature of circadian regulation as mice also exhibit rhythms in alcohol sensitivity with increased sensitivity during the day (inactive period) and decreased sensitivity at night (active period) [291]. Humans show time-of-day rhythms in the consumption of alcohol and alcohol sensitivity [292, 293]. However, not all alcohol-induced behaviors are directly regulated by the circadian clock. In Drosophila, the degree of rapid tolerance assessed at four hours does not show dependence upon the time of alcohol exposure, although rhythms are observed in the loss of righting reflex in both the initial alcohol exposure and the test exposure [290]. Alcohol absorbance also does not vary based upon time of exposure [290] or between circadian clock mutants and wild-type flies [294].

6.2. Circadian Dysfunction Increases Alcohol Sensitivity. When the circadian clock is rendered nonfunctional through either genetic or environmental manipulations, Drosophila exhibits significantly increased behavioral sensitivity to alcohol [202]. per $^{01}$ mutant flies are more susceptible to alcohol-induced sedation with significantly shorter alcohol exposure required for sedation and longer recovery times to regain postural control compared to wild-type flies [202]. Constant light is frequently used in Drosophila as an environmental method to ablate molecular and behavioral circadian rhythmicity without the need for genetic manipulations [150, 290, 295-297] as genetic mutations or constitutive knockouts present during development may affect neural circuitry thus influencing adult behavior. Flies housed in constant light exhibit increased sensitivity to alcohol and longer recovery times [202, 290]. Circadian arrhythmicity arising from the per $^{01}$ mutation or constant light exposure also appears associated with increased alcohol-induced mortality in Drosophila [298]. 
Disruption of the circadian oscillator affects alcohol behaviors and toxicity across species. mPer 2 mutant mice display increased voluntary alcohol intake and fail to exhibit diurnal rhythms in the behavioral response to alcohol [291, 299]. In humans, the regulation of alcohol consumption appears altered with gene variations in hper 2 determined by single-nucleotide polymorphism analysis correlated with higher or lower alcohol consumption [299, 300]. The Per2 gene and the circadian clock have also been postulated to play a role in regulating developmental changes following alcohol exposure as mper 2 mutant mice fail to exhibit the persistent hypothalamic changes associated with early-life alcohol exposure in wild-type mice [301]. In mice, genetic or environmental disruption of the circadian clock increases alcohol-induced pathologies including intestinal permeability and hepatic inflammation [302] and significantly alters gene expression for many genes involved in inflammation or metabolic responses [303]. Alcohol-induced colorectal cancer in mice is also increased with circadian desynchronization from shifting light-dark cycles [304]. In humans, circadian misalignment in night-shift workers is postulated to be a contributing factor to the development of liver injury with alcohol consumption [30]. Thus, circadian desynchronization appears to be a key factor in alcohol sensitivity and alcohol-induced pathologies across species.

6.3. Circadian Clock and Alcohol Tolerance. The development of alcohol tolerance and associated changes in neural plasticity also appears to require a functional circadian clock, even though the degree of rapid tolerance following alcohol exposure does not vary with time of day [290]. Flies with mutations in core oscillator genes including per $^{01}$ and $\mathrm{tim}^{01}$ fail to develop functional tolerance following alcohol exposure while $c y c^{01}$ flies only acquire weak tolerance [294]. Flies with the circadian clock rendered nonfunctional by constant light also fail to develop tolerance [294]. However, mutant $\mathrm{Clk}^{\text {Jrk }}$ flies develop tolerance similar to that of wild-type flies raising the possibility that PER and other core clock components regulate alcohol-induced behaviors independent of the circadian clock [294].

6.4. Effect of Alcohol on the Circadian Clock. The interactions between the circadian clock and alcohol are bidirectional. In rodent models, acute and chronic alcohol exposure results in phase shifts in locomotor activity rhythms and alters the ability of the circadian system to respond to perturbations [305-308]. Furthermore, chronic alcohol administration alters SCN function by disrupting the SCN responsiveness to light and nonphotic resetting as shown through in vivo and in vitro studies [305, 309]. Chronic alcohol exposure also affects neuropeptide signaling in the SCN decreasing the amount of vasopressin and VIP in SCN neurons [286]. In humans, chronic alcohol use or acute binge alcohol consumption appear to be strongly linked to sleep and circadian disorders $[3,310,311]$. The mRNA expression of clk1, bmal1, per2, cry 1 , and cry 2 is significantly reduced in alcoholic patients [312]. However, unlike rodent models, a single acute alcohol exposure in humans does not appear sufficient to affect the phase-shifting ability of the circadian system [313].

Alcohol differentially affects central and peripheral oscillators. Studies in mice and rats demonstrate that repeated alcohol exposure results in major alterations in peripheral rhythms reducing the correlation in the phase relationships between body temperature and activity rhythms as well as altering and blunting the rhythms in plasma corticosterone, glucose, lactic acid, triglycerides, and cholesterol [287, 314, 315]. Distinct tissue-specific interactions and changes in gene expression have also been observed following chronic alcohol use in clock mutant mice for the hippocampus, liver, and colon [303]. Alcohol administration increases CLOCK and PER2 protein levels in intestinal epithelial cell cultures and increases measures of alcoholinduced permeability [316]. At the molecular level, chronic alcohol exposure appears to have the greatest effect on phase shifts or disruptions of core clock and clock-controlled genes in the liver rather than in the SCN [315, 317]. Chronic alcohol phase advances the rhythms in Per1 expression in the adrenal and pituitary clocks and Per2 expression in the liver clocks, without affecting the molecular clock in the SCN resulting in discord in the phase relationships between the SCN and peripheral oscillators [314, 317]. However, earlier research suggested that chronic alcohol administration affected the rhythmic expression of proopiomelanocortin, Per2, and Per3 in the SCN [318].

Bidirectional interactions between alcohol and the circadian clock are also conserved in Drosophila. For example, developmental alcohol exposure during the third larval instar affects period length in adult flies $[319,320]$. With substantial evidence attesting to the value of Drosophila as a model for alcohol research and the parallels between the interactions of the circadian system with alcohol neurobiology across species (see Table 2), Drosophila appears poised for future studies probing the mechanism through which the circadian clock modulates these behaviors.

\section{Interactions of the Circadian System with Cocaine}

7.1. Circadian Modulation of Cocaine Behaviors. One of the earliest hints of an interaction between cocaine and the circadian system arose from studies of patients with seasonal affective disorder and seasonal variations in cocaine abuse $[321,322]$. Subsequent research in rodent models found that the effects of acute cocaine exposure on locomotor activity were dependent upon the time of day [323] as was cocaineinduced behavioral sensitization [324-326]. Similar to alcohol behaviors, cocaine sensitization appears lowest during the night [324-326] correlated with the animal's activity period. Cocaine self-administration also varies with the circadian cycle [327] suggesting strong interactions between cocaine and the circadian system.

7.2. Cocaine's Effects on the Circadian Clock. Similar to alcohol, cocaine also bidirectionally interacts with the circadian clock. Cocaine administration disrupts light-induced phase shifts of the SCN during the night while cocaine 
TABLE 2: Genes that mediate circadian and alcohol interactions.

\begin{tabular}{|c|c|c|c|c|c|}
\hline Fly ortholog & $\begin{array}{c}\text { Encoded } \\
\text { protein }\end{array}$ & $\begin{array}{c}\text { Genetic } \\
\text { manipulation }\end{array}$ & $\begin{array}{c}\text { Drosophila alcohol-related } \\
\text { phenotypes }\end{array}$ & $\begin{array}{c}\text { Mammalian } \\
\text { homolog }\end{array}$ & References \\
\hline$p e r^{01}$ & PER & $\downarrow$ expression & $\begin{array}{c}\uparrow \text { alcohol sensitivity } \\
\downarrow \text { rapid tolerance } \\
\uparrow \text { recovery time }\end{array}$ & $\begin{array}{l}\text { mPer1; } \\
\text { mPer2 }\end{array}$ & {$[202,290,291,294,299,301,318]$} \\
\hline $\mathrm{tim}^{01}$ & TIM & $\downarrow$ expression & $\begin{array}{c}\uparrow \text { alcohol sensitivity } \\
\downarrow \text { rapid tolerance }\end{array}$ & - & [294] \\
\hline$c y c^{01}$ & CYCLE & $\downarrow$ expression & $\begin{array}{c}\uparrow \text { alcohol sensitivity } \\
\downarrow \text { rapid tolerance }\end{array}$ & BMAL & {$[30,294]$} \\
\hline$C l k^{J R K}$ & CLOCK & $\downarrow$ expression & No change & CLOCK & {$[294,434]$} \\
\hline
\end{tabular}

TABLe 3: Genes mediating circadian and drug interactions in flies and mammals.

\begin{tabular}{|c|c|c|c|c|c|}
\hline Gene/manipulation & $\begin{array}{c}\text { Mechanism } \\
\text { of action }\end{array}$ & $\begin{array}{l}\text { Drug-related phenotypes } \\
\text { in Drosophila }\end{array}$ & Reference & $\begin{array}{c}\text { Drug studied in } \\
\text { mammals }\end{array}$ & Reference \\
\hline per ${ }^{01}$ & $\begin{array}{l}\text { Regulation of } \\
\text { circadian rhythms }\end{array}$ & $\begin{array}{c}\downarrow \text { behavioral sensitization } \\
\text { to cocaine }\end{array}$ & {$[334]$} & $\begin{array}{l}\text { mPer } 1 \text { and mPer2: cocaine, } \\
\text { morphine, and } \\
\text { amphetamines }\end{array}$ & {$[324,326,336,435,436]$} \\
\hline$c l k$ & $\begin{array}{l}\text { Regulation of } \\
\text { circadian rhythms }\end{array}$ & $\begin{array}{c}\downarrow \text { behavioral sensitization } \\
\text { to cocaine }\end{array}$ & {$[334]$} & $\begin{array}{l}\text { Clk: cocaine, morphine, } \\
\text { and amphetamines }\end{array}$ & {$[324,336,437,438]$} \\
\hline$c y c^{01}$ & $\begin{array}{l}\text { Regulation of } \\
\text { circadian rhythms }\end{array}$ & $\begin{array}{c}\downarrow \text { behavioral sensitization } \\
\text { to cocaine }\end{array}$ & {$[334]$} & $\begin{array}{l}\text { Bmal: cocaine and } \\
\text { amphetamine }\end{array}$ & {$[324,336,436]$} \\
\hline $\operatorname{tim}^{01}$ & $\begin{array}{l}\text { Regulation of } \\
\text { circadian rhythms }\end{array}$ & $\begin{array}{l}\text { No change in response } \\
\text { to cocaine }\end{array}$ & {$[334]$} & - & - \\
\hline$d b t$ & $\begin{array}{l}\text { Regulation of } \\
\text { circadian rhythms }\end{array}$ & $\begin{array}{c}\downarrow \text { behavioral sensitization } \\
\text { to cocaine }\end{array}$ & {$[334]$} & $\begin{array}{c}\text { Csnk1?: cocaine, } \\
\text { amphetamines, and opiods }\end{array}$ & {$[439-442]$} \\
\hline$d L m o$ & $\begin{array}{c}\text { Regulation of } \\
\text { dopamine receptor } \\
\text { expression }\end{array}$ & $\begin{array}{l}\uparrow \text { sensitivity to cocaine } \\
\text { and nicotine and weak } \\
\text { circadian rhythms in } \\
\text { locomotor activity }\end{array}$ & [333] & Lmo4: cocaine & {$[338,443]$} \\
\hline
\end{tabular}

administration during the day induces phase advances as shown through in vivo studies in mice and in vitro studies using SCN slices [328, 329]. The effects of cocaine on phase shifting of the circadian clock appear mediated through serotonin transporter antagonism and Per2 [329]. Repeated cocaine exposure has also been shown to differentially affect per2 gene expression in the caudate putamen in rats [330].

7.3. Genes Mediating Circadian Cocaine Responses. At the first glance, Drosophila may seem an unusual model to forward the studies of drug abuse, but the extent of readily available mutants and the ease of behavioral screens accelerated the identification of genes involved in circadian-cocaine interactions (Table 3). In response to cocaine, Drosophila exhibits motor and reflexive behaviors including grooming and locomotor circling similar to those of mammals [331-333]. One of the first studies demonstrating the interplay between circadian genes and the drugs of abuse showed that flies with mutations in the circadian gene per failed to sensitize to cocaine (indicated by erratic jumping, twirling, and paralysis) even after repeated exposures to cocaine compared to wild-type Canton-S flies [334]. However, per mutants with altered period length rather than arrhythmicity display differential responses to cocaine; per $^{S}$ mutants exhibit increased responsiveness followed by a weak sensitization to cocaine exposure while per $^{L}$ mutants show normal initial behavioral responses to cocaine but no sensitization [334].

This research spurred subsequent studies in mice examining the relationship between per and cocaine responsiveness. In mice, the period gene also appears strongly linked to cocaine behaviors. Mice with a mutation in $m P e r 1$ do not sensitize to cocaine [324], and circadian rhythms in Perl expression in the striatum appear necessary for rhythms in cocaine sensitization [326]. Recently, a variable repeat polymorphism in hPer2 was correlated with higher expression in cocaineaddicted individuals and cocaine users [335]. mPer2 mutant mice display hypersensitization to cocaine, although they exhibit normal levels of conditioned place preference (CPP) with cocaine reward [324].

Additional evidence for the role of PER in cocaine responses comes from studies of flies with mutations in proteins that interact with PER. Flies with a mutation in doubletime (homolog of casein kinase 1-epsilon) require a higher dosage of cocaine to exhibit cocaine-induced behaviors with the first cocaine exposure but do not show significant sensitization with multiple exposures [334]. CLK and CYC mutant flies display increased initial sensitivity to cocaine compared to wild-type flies but fail to develop sensitization following the second exposure [334]. In mammals, additional circadian genes have also been implicated 
in cocaine responses. Clock ${ }^{\Delta 19}$ mutant mice exhibit increased cocaine self-administration and conditioned place preference in response to cocaine compared to wild-type mice [336, 337].

While the above studies highlight the role of multiple circadian genes, particularly per, in mediating drug-induced behaviors, the function of these genes in drug behaviors may be distinct from their function in the regulation of the circadian clock. For example, $\operatorname{tim}^{0}$ flies exhibit behavioral responses to cocaine similar to wild-type flies suggesting a divergence between the regulation of circadian function and that of cocaine behavior [334]. Intriguingly, regulation of cocaine behaviors appears to involve the small ventral lateral neurons in Drosophila, considered circadian pacemaker neurons, although neurotransmission through the primary circadian neuropeptide PDF is not required for cocaine behavioral responses [333]. Within the small ventral lateral neurons, the Lim-only gene lmo appears involved in both cocaine sensitization and circadian locomotor activity rhythms. Imo expression/function is inversely correlated with cocaine sensitivity as mutants with low levels of LMO exhibit increased cocaine sensitivity while flies in which overexpression of LMO occurs demonstrate increased resistance to the acute effects of cocaine [333]. Imo mutant flies display poor locomotor activity rhythms. In mice, $\operatorname{lmo} 4$ also regulates cocaine sensitization [221] and the expression of $\operatorname{lmo} 4$ is regulated by the circadian clock [338] reinforcing the relationship between the circadian clock and cocaine behaviors.

7.4. Circadian Regulation of the Reward System. A conserved feature of circadian influence on drug abuse and addiction arises from circadian regulation of the reward system. Biogenic amines produced in both the central and peripheral nervous system control motor behaviors in vertebrates and invertebrates [339-342]. Cocaine and other drugs of abuse act directly on the mesolimbic dopamine system and other pathways to promote drug-seeking behavior. In mammals and flies during reward learning, the valence and reward properties of a stimulus involve dopamine signaling, glutamate, and GABA in a complex feedback and feedforward network [343, 344]. In Drosophila, reward learning requires dopaminergic projections to the mushroom body neurons $[125,345]$ whereas in mammals, dopaminergic innervation from the ventral tegmental area to the striatum, the bed nucleus of the stria terminalis, and the nucleus accumbens is required for reward preference [346].

In Drosophila and mammals, the responsiveness of dopamine receptors is regulated by the circadian clock and dependent on functional expression of the per gene [347-349]. Using direct application of a D2 agonist, quinpirole, to the D2 receptors of the ventral nerve cord, Andretic and colleagues found that functional circadian genes are necessary for behavioral responses to cocaine in behaviorally active decapitated flies [334]. Furthermore, flies with mutations in per, clock, or cycle show no induction of tyrosine decarboxylase activity (TDC) which is necessary for the synthesis of tyramine, an important element for cocaine sensitization in Drosophila [332, 334]. Similarly in mammals, mice mutant in Clock show increased tyrosine hydroxylase $(\mathrm{TH})$, the rate-limiting enzyme for dopamine synthesis as well as other dopamine-related genes, and increased cocaine CPP [336]. Furthermore, many of the diurnal differences in cocaine self-administration may be due to the regulation of dopaminergic transmission. Andretic and Hirsh [347] identified diurnal regulation of dopamine receptor responsiveness in Drosophila. Likewise in mammals, most of the components of dopaminergic transmission including the dopamine receptor, dopamine transporter, and tyrosine hydroxylase exhibit diurnal rhythms [350-352]. More detailed discussions of the interactions of the circadian system with drug neurobiology in mammals may be found in recent reviews [348, 353-355].

Per1-knockout mice fail to display conditioned place preference (CPP) with cocaine reward [324] which is regulated by the circadian clock through the pineal gland and melatonin [356]. Recently, melatonin also was shown to significantly reduce motivation for cocaine and cocaine-seeking behavior in rats [357]. In summary, these studies suggest that a functional core circadian oscillator is necessary to drive pineal gland/melatonin outputs that regulate striatal per1 gene expression to affect cocaine behaviors. However, the relationship between per1 regulation and cocaine behavior is complicated as Per1 mutant mice self-administer cocaine and display reinstatement of cocaine administration following extinction similar to wild-type counterparts [358]. This is reminiscent of the differential circadian modulation of alcohol-induced behaviors and suggests different neurobiological mechanisms underlying various drug behaviors.

7.5. Impact of Drosophila Circadian Cocaine Research. Despite the successes with the use of Drosophila as a model for investigations of drug abuse, surprisingly little research in Drosophila has been performed in the past few years delineating additional circadian-drug interactions outside of alcohol neurobiology. However, the research in Drosophila identifying links between PER and cocaine sensitization directly fostered research in mammals investigating circadian interactions with morphine [359-361] and methamphetamine [362]. Thus, research in Drosophila has provided impetus and conceptual advances in our understanding of the influence of the circadian clock on behavioral responses to drugs as well outlining roles circadian genes and neurons can play outside of the circadian clock in drug responses.

\section{Potential Avenues for Future Drosophila Research}

Despite the progress in research outlining connections between the circadian system, substance abuse, and the reward system, our understanding of the scope of these interactions and the underlying mechanisms through which these connections occur remains limited in both Drosophila and mammalian models directly impacting the prevention and treatment of drug-induced pathologies and addiction disorders. Techniques in rodent models have rapidly advanced over the past decade with sophisticated innovations permitting tissue-specific manipulations in gene expression and neuronal activity. Despite these advances, research in rodent 
models remains expensive and time consuming, reinforcing a need for the continued use of alternative model systems. The ease of maintenance, relatively short lifespan, and the neurogenetic approaches possibly have permitted Drosophila to remain at the forefront of neuroscience and disease research facilitating more targeted research in mammalian models. Primary areas of circadian-drug research in which Drosophila could provide advancement can be grouped into three strategic classifications: (1) system-level research (behavioral sensitivity and pathology) for defining the interactions between the circadian clock, sleep, and substance abuse; (2) identification of molecular networks for identifying the connections between the circadian system and substance neurobiology; and (3) drug discovery and small-molecule screening for therapy development.

8.1. System-Level Research. Behavioral research has exposed bidirectional interactions between the circadian system and substance abuse; however, the scope of these interactions remains undefined. Alcohol and cocaine represent the only drugs of abuse for which circadian interactions have been studied in Drosophila. Yet, considerable research has been done on dopaminergic signaling and reward pathways in Drosophila with significant parallels shown to mammals making Drosophila a suitable choice for studies of additional drugs of abuse. For example, dopamine and octopamine modulate the acute activating effects of nicotine on locomotion and the startle response [261,363]. As substance abuse is often comorbid with additional substance abuse, poor nutrition, or sleep disorders, the ease of large-scale behavioral studies in Drosophila facilitates combinatorial studies.

The effects of other drugs of abuse including nicotine, morphine, amphetamine, and cannabinoids have been studied in Drosophila [364-366], expanding the possibilities for further investigation of the bidirectional interactions between the circadian clock and drug neurobiology using Drosophila. Comparatively little research has been done to dissect the relationship between endocannabinoid or cannabinoid use and circadian clock function in humans or rodent models [367-369]. However, research has shown that cannabinoids can excite circadian clock neurons, and this may be linked to the behavioral effects of time dissociation experienced by marijuana users [370, 371]. Given the increasing prevalence of marijuana use with the number of users in the United States more than doubling since 2002 to $9.5 \%$ of the adult population and approximately $30 \%$ of those individuals meeting the criteria for addiction [372], more research is needed on the interactions of marijuana with the circadian clock. The physiological activities of endocannabinoids on cell signaling appear conserved between Drosophila and mammalian systems [373], and Drosophila has been used to investigate the role of cannabinoids as therapeutics $[374,375]$. As concurrent use of marijuana and alcohol increases the effects of the individual drugs [376-378], combinatorial studies are needed. Thus, Drosophila may be a practical model for fast high-throughput studies translatable to mammalian models.

Considerably more behavioral research is needed to identify circadian modulation of sensitivity or toxicity encompassing multiple exposure paradigms across age groups. The circadian system weakens with age across species resulting in damped molecular rhythms and altered behavioral and metabolic rhythms $[89,379,380]$. In both humans and animal models, older subjects demonstrate greater difficulty in phase shifting after perturbations to the circadian system [381, 382]. The weakening of the circadian system with age may contribute to the increased sensitivity to or toxicity of drugs of abuse observed in older individuals. In rodent models, aged animals appear more sensitive to the effects of alcohol and alcohol withdrawal [383, 384], although little research has been done examining circadian interactions with alcohol or drugs of abuse in aged animals. With its relatively short lifespan, Drosophila is an excellent system for the aging system with analogous age-related changes to those observed in rodent models and humans.

8.2. Molecular Networks. With approximately 20,000 estimated human genes and an untold number of regulatory elements [385], identifying the underlying molecular or genetic mechanisms for complex behavioral and physiological issues remains an enormous challenge without potential candidates identified from animal models. This is particularly true for substance abuse disorders affecting the central nervous system that also result in widespread damage across tissues. Despite the neuroanatomical and morphological differences separating flies from humans, parallels exist for disease research affecting the central nervous system, heart, liver, kidneys, and gut [386], crucial organs for understanding the addictive and pathophysiological impacts of drug abuse.

Drosophila orthologs have been identified for approximately $75 \%$ of known human disease genes [105, 386-390]. The rapid cross-species translational value of Drosophila research has been demonstrated in alcohol neurobiology through the identification of the epidermal growth factor signaling pathway [195] and the role of a tyrosine kinase receptor, anaplastic lymphoma kinase [223], and the transcriptional regulator Lmo in alcohol behaviors [221]. Likewise, Drosophila has provided a model for the identification of candidate genes involved in addiction and reward behaviors $[71,139,391]$. The wide repertoire of tools in Drosophila to permit cost-effective large-scale genetic screens includes genome-wide RNAi screens with available collections of RNAi transgenic lines against every Drosophila gene [392], complete sets of micro RNA sponges with conditional expression possible [124, 393], and CRISPR-mediated mutations [394, 395].

8.3. Drug Discovery. The identification of new drugs for pharmaceutical use starting with target identification or small-molecule screening is a lengthy and expensive process often lasting more than a decade with costs up to $\$ 1$ billion [396]. To streamline this process, high-throughput screens in Drosophila and other invertebrate models such as C. elegans have been employed more frequently in the past few years as a platform for target identification, drug discovery, and small-molecule screening. Previous research has demonstrated the predictive validity of Drosophila in preclinical 
research. Drosophila has proven beneficial for the validation and development of cancer drugs as well as for screening previously approved drugs for alternate purposes [397]. The tractability of Drosophila for large-scale screens include (1) viability and development assays for embryos, larvae, pupae, and adults; (2) whole-organism drug screens for absorption, metabolism, or toxicity; and (3) reporter assays including luciferase or GFP expression assays [397]. With the high degree of phylogenetic conservation in cellular signaling pathways, mechanistically the similarities between the Drosophila and mammalian circadian system make Drosophila an ideal platform for drug discovery for the identification of potential targets or therapeutics impacting the circadian system.

Through the ages, technological innovations have engineered societal changes transforming cultural norms and causing the urbanization of societies. Rapid advances in communication, networking, and information dissemination in the past two decades have solidified the establishment of a 24/7 global society further contributing to the rise of individual circadian and sleep disorders. The swiftness with which these technology-driven societal and cultural changes have become entrenched in children, adolescents, and adults makes it unlikely that the physical and mental health problems arising from circadian and sleep disorders will vanish. Thus, there is a critical need for continued research to delineate the mechanisms through which the circadian clock or circadian dysfunction affects substance abuse and conversely how substance abuse contributes to alterations in the functioning of the circadian system. Renewed research emphasis on invertebrate models as a practical and economical model to tackle these problems will provide basic biological insights into molecular pathways and cellular interactions associated with defined behaviors that can subsequently be investigated in more complex model systems with rapid translational impacts. Research in Drosophila has the capability to advance the understanding of the molecular changes or the genetic risk factors that transform substance use to abuse and addiction potentially providing new avenues for the identification of therapeutic interventions to minimize the risk of drug abuse and drug toxicity.

\section{Conflicts of Interest}

The authors declare that they have no conflicts of interest.

\section{Acknowledgments}

This work was supported by the National Institute on Alcohol Abuse and Alcoholism Grant R21AA021233.

\section{References}

[1] J. J. Sacks, K. R. Gonzales, E. E. Bouchery, L. E. Tomedi, and R. D. Brewer, "2010 national and state costs of excessive alcohol consumption," American Journal of Preventive Medicine, vol. 49, no. 5, pp. e73-e79, 2015.

[2] J. M. McGinnis and W. H. Foege, "Mortality and morbidity attributable to use of addictive substances in the United
States," Proceedings of the Association of American Physicians, vol. 111, no. 2, pp. 109-118, 1999.

[3] D. A. Conroy and J. T. Arnedt, "Sleep and substance use disorders: an update," Current Psychiatry Reports, vol. 16, no. 10, p. 487, 2014.

[4] SAMSHA, Results from the 2013 National Survey on Drug Use and Health. Summary of National Findings, NSDUH Series H-48, HHS Publication No. (SMA) 14-4863(Substance Abuse and Mental Health Services Administration), Rockville, MD, USA, 2014.

[5] J. Rehm, C. Mathers, S. Popova, M. Thavorncharoensap, Y. Teerawattananon, and J. Patra, "Global burden of disease and injury and economic cost attributable to alcohol use and alcohol-use disorders," The Lancet, vol. 373, no. 9682, pp. 2223-2233, 2009.

[6] A. H. Mokdad, J. S. Marks, D. F. Stroup, and J. L. Gerberding, "Actual causes of death in the United States, 2000," JAMA, vol. 291, no. 10, pp. 1238-1245, 2004.

[7] D. Kanny, R. D. Brewer, J. B. Mesnick, L. J. Paulozzi, T. S. Naimi, and H. Lu, "Vital signs: alcohol poisoning deaths - United States, 2010-2012," Morbidity and Mortality Weekly Report, vol. 63, no. 53, pp. 1238-1242, 2015.

[8] H. G. Birnbaum, A. G. White, M. Schiller, T. Waldman, J. M. Cleveland, and C. L. Roland, "Societal costs of prescription opioid abuse, dependence, and misuse in the United States," Pain Medicine, vol. 12, no. 4, pp. 657-667, 2011.

[9] X. Xu, E. E. Bishop, S. M. Kennedy, S. A. Simpson, and T. F. Pechacek, "Annual healthcare spending attributable to cigarette smoking: an update," American Journal of Preventive Medicine, vol. 48, no. 3, pp. 326-333, 2015.

[10] C. S. Florence, C. Zhou, F. Luo, and L. Xu, "The economic burden of prescription opioid overdose, abuse, and dependence in the United States, 2013," Medical Care, vol. 54, no. 10, pp. 901-906, 2016.

[11] A. Hughes, M. R. Williams, R. N. Lipari, and S. Van Horn, "State estimates of past year cocaine use among young adults: 2014 and 2015," The CBHSQ Report, Center for Behavioral Health Statistics and Quality, Substance Abuse and Mental Health Services Administration, Rockville, MD, USA, 2016.

[12] R. E. Mistlberger and D. J. Skene, "Social influences on mammalian circadian rhythms: animal and human studies," Biological Reviews of the Cambridge Philosophical Society, vol. 79, no. 3, pp. 533-556, 2004.

[13] T. Roenneberg and M. Merrow, "The circadian clock and human health," Current Biology, vol. 26, no. 10, pp. R432R443, 2016.

[14] U. Schibler, I. Gotic, C. Saini et al., "Clock-talk: interactions between central and peripheral circadian oscillators in mammals," Cold Spring Harbor Symposia on Quantitative Biology, vol. 80, pp. 223-232, 2015.

[15] J. Bass and J. S. Takahashi, "Circadian integration of metabolism and energetics," Science, vol. 330, no. 6009, pp. 1349-1354, 2010.

[16] W. Huang, K. M. Ramsey, B. Marcheva, and J. Bass, "Circadian rhythms, sleep, and metabolism," Journal of Clinical Investigation, vol. 121, no. 6, pp. 2133-2141, 2011.

[17] M. V. Plikus, E. N. Van Spyk, K. Pham et al., “The circadian clock in skin: implications for adult stem cells, tissue regeneration, cancer, aging, and immunity," Journal of Biological Rhythms, vol. 30, no. 3, pp. 163-182, 2015. 
[18] M. Wittmann, M. Paulus, and T. Roenneberg, "Decreased psychological well-being in late 'chronotypes' is mediated by smoking and alcohol consumption," Substance Use \& Misuse, vol. 45, no. 1-2, pp. 15-30, 2010.

[19] B. P. Hasler, S. L. Sitnick, D. S. Shaw, and E. E. Forbes, “An altered neural response to reward may contribute to alcohol problems among late adolescents with an evening chronotype," Psychiatry Research, vol. 214, no. 3, pp. 357-364, 2013.

[20] U. Broms, J. Kaprio, C. Hublin, M. Partinen, P. A. Madden, and M. Koskenvuo, "Evening types are more often current smokers and nicotine-dependent-a study of Finnish adult twins," Addiction, vol. 106, no. 1, pp. 170-177, 2011.

[21] S. S. Gau, C. Y. Shang, K. R. Merikangas, Y. N. Chiu, W. T. Soong, and A. T. Cheng, "Association between morningness-eveningness and behavioral/emotional problems among adolescents," Journal of Biological Rhythms, vol. 22, no. 3, pp. 268-274, 2007.

[22] B. P. Hasler and D. B. Clark, "Circadian misalignment, reward-related brain function, and adolescent alcohol involvement," Alcoholism, Clinical and Experimental Research, vol. 37, no. 4, pp. 558-565, 2013.

[23] T. Bogg, P. R. Finn, and K. E. Monsey, "A year in the college life: evidence for the social investment hypothesis via trait self-control and alcohol consumption," Journal of Research in Personality, vol. 46, no. 6, pp. 694-699, 2012.

[24] U. Albrecht, "The circadian clock, metabolism and obesity," Obesity Reviews, vol. 18, Supplement 1, pp. 25-33, 2017.

[25] G. R. Sridhar and N. S. Sanjana, "Sleep, circadian dysrhythmia, obesity and diabetes," World Journal of Diabetes, vol. 7, no. 19, pp. 515-522, 2016.

[26] F. A. Scheer, M. F. Hilton, C. S. Mantzoros, and S. A. Shea, "Adverse metabolic and cardiovascular consequences of circadian misalignment," Proceedings of the National Academy of Sciences of the United States of America, vol. 106, no. 11, pp. 4453-4458, 2009.

[27] D. M. Arble, K. M. Ramsey, J. Bass, and F. W. Turek, "Circadian disruption and metabolic disease: findings from animal models," Best Practice \& Research Clinical Endocrinology \& Metabolism, vol. 24, no. 5, pp. 785-800, 2010.

[28] A. W. McHill and K. P. Wright, "Role of sleep and circadian disruption on energy expenditure and in metabolic predisposition to human obesity and metabolic disease," Obesity Reviews, vol. 18, Supplement 1, pp. 15-24, 2017.

[29] B. P. Hasler, L. J. Smith, J. C. Cousins, and R. R. Bootzin, "Circadian rhythms, sleep, and substance abuse," Sleep Medicine Reviews, vol. 16, no. 1, pp. 67-81, 2012.

[30] G. R. Swanson, A. Gorenz, M. Shaikh et al., "Night workers with circadian misalignment are susceptible to alcoholinduced intestinal hyperpermeability with social drinking," American Journal of Physiology - Gastrointestinal and Liver Physiology, vol. 311, no. 1, pp. G192-G201, 2016.

[31] A. R. Meyers and M. W. Perrine, "Drinking by police officers, general drivers and late-night drivers," Journal of Studies on Alcohol, vol. 57, no. 2, pp. 187-192, 1996.

[32] A. S. Keuroghlian, A. S. Barry, and R. D. Weiss, "Circadian dysregulation, zolpidem dependence, and withdrawal seizure in a resident physician performing shift work," The American Journal on Addictions, vol. 21, no. 6, pp. 576-577, 2012.

[33] K. S. Kendler, H. Ohlsson, J. Sundquist, and K. Sundquist, "Alcohol use disorder and mortality across the lifespan: a longitudinal cohort and co-relative analysis," JAMA Psychiatry, vol. 73, no. 6, pp. 575-581, 2016.

[34] H. Wan, D. Goodkind, and P. Kowal, An Aging World: 2015, U.S. Census Bureau, International Population Reports, Washington, DC, USA, 2015, P95(16-1).

[35] C. C. Caruso, E. M. Hitchcock, R. B. Dick, J. M. Russo, and J. M. Schmit, Overtime and Extended Work Shifts: Recent Findings on Illnesses, Injuries and Health Behavior, U.S. Department of Health and Human Services, Centers for Disease control and Prevention, Cincinatti, OH, USA, 2004.

[36] T. Alterman, S. E. Luckhaupt, J. M. Dahlhamer, B. W. Ward, and G. M. Calvert, "Prevalence rates of work organization characteristics among workers in the U.S.: data from the 2010 National Health Interview Survey," American Journal of Industrial Medicine, vol. 56, no. 6, pp. 647-659, 2013.

[37] Institute of Medicine (US) Committee on Sleep Medicine and Research, H. R. Colten, and B. M. Altevogt, Sleep Disorders and Sleep Deprivation: An Unmet Public Health Problem, National Academies Press, Washington, DC, USA, 2006.

[38] A. D. Laposky, E. Van Cauter, and A. V. Diez-Roux, "Reducing health disparities: the role of sleep deficiency and sleep disorders," Sleep Medicine, vol. 18, pp. 3-6, 2016.

[39] K. G. Lambert, R. J. Nelson, T. Jovanovic, and M. Cerdá, "Brains in the city: neurobiological effects of urbanization," Neuroscience \& Biobehavioral Reviews, vol. 58, pp. 107-122, 2015.

[40] C. J. Matz, D. M. Stieb, K. Davis et al., "Effects of age, season, gender and urban-rural status on time-activity: Canadian Human Activity Pattern Survey 2 (CHAPS 2)," International Journal of Environmental Research and Public Health, vol. 11, no. 2, pp. 2108-2124, 2014.

[41] R. C. Espiritu, D. F. Kripke, S. Ancoli-Israel et al., "Low illumination experienced by San Diego adults: association with atypical depressive symptoms," Biological Psychiatry, vol. 35, no. 6, pp. 403-407, 1994.

[42] B. L. Diffey, "An overview analysis of the time people spend outdoors," British Journal of Dermatology, vol. 164, no. 4, pp. 848-854, 2011.

[43] M. H. Smolensky, L. L. Sackett-Lundeen, and F. Portaluppi, "Nocturnal light pollution and underexposure to daytime sunlight: complementary mechanisms of circadian disruption and related diseases," Chronobiology International, vol. 32, no. 8, pp. 1029-1048, 2015.

[44] R. M. Lunn, D. E. Blask, A. N. Coogan et al., "Health consequences of electric lighting practices in the modern world: a report on the National Toxicology Program's workshop on shift work at night, artificial light at night, and circadian disruption," Science of The Total Environment, vol. 607-608, pp. 1073-1084, 2017.

[45] T. A. Bedrosian and R. J. Nelson, "Timing of light exposure affects mood and brain circuits," Translational Psychiatry, vol. 7, no. 1, article e1017, 2017.

[46] F. Falchi, P. Cinzano, D. Duriscoe et al., "The new world atlas of artificial night sky brightness," Science Advances, vol. 2, no. 6, article e1600377, 2016.

[47] S. Hattar, H. W. Liao, M. Takao, D. M. Berson, and K. W. Yau, "Melanopsin-containing retinal ganglion cells: architecture, projections, and intrinsic photosensitivity," Science, vol. 295, no. 5557, pp. 1065-1070, 2002.

[48] S. Hattar, R. J. Lucas, N. Mrosovsky et al., "Melanopsin and rod-cone photoreceptive systems account for all major 
accessory visual functions in mice," Nature, vol. 424, no. 6944, pp. 76-81, 2003.

[49] K. J. Navara and R. J. Nelson, "The dark side of light at night: physiological, epidemiological, and ecological consequences," Journal of Pineal Research, vol. 43, no. 3, pp. 215-224, 2007.

[50] L. K. Fonken, J. L. Workman, J. C. Walton et al., "Light at night increases body mass by shifting the time of food intake," Proceedings of the National Academy of Sciences of the United States of America, vol. 107, no. 43, pp. 1866418669, 2010.

[51] I. Kloog, A. Haim, R. G. Stevens, M. Barchana, and B. A. Portnov, "Light at night co-distributes with incident breast but not lung cancer in the female population of Israel," Chronobiology International, vol. 25, no. 1, pp. 65-81, 2008.

[52] C. C. Kyba, K. P. Tong, J. Bennie et al., "Worldwide variations in artificial skyglow," Scientific Reports, vol. 5, p. 8409, 2015.

[53] K. P. Wright, A. W. McHill, B. R. Birks, B. R. Griffin, T. Rusterholz, and E. D. Chinoy, "Entrainment of the human circadian clock to the natural light-dark cycle," Current Biology, vol. 23, no. 16, pp. 1554-1558, 2013.

[54] M. H. Hagenauer and T. M. Lee, "The neuroendocrine control of the circadian system: adolescent chronotype," Frontiers in Neuroendocrinology, vol. 33, no. 3, pp. 211-229, 2012.

[55] T. Roenneberg, T. Kuehnle, P. P. Pramstaller et al., "A marker for the end of adolescence," Current Biology, vol. 14, no. 24, pp. R1038-R1039, 2004.

[56] S. J. Crowley, C. Acebo, and M. A. Carskadon, "Sleep, circadian rhythms, and delayed phase in adolescence," Sleep Medicine, vol. 8, no. 6, pp. 602-612, 2007.

[57] C. Cajochen, S. Frey, D. Anders et al., "Evening exposure to a light-emitting diodes (LED)-backlit computer screen affects circadian physiology and cognitive performance," Journal of Applied Physiology, vol. 110, no. 5, pp. 1432-1438, 2011.

[58] J. H. Oh, H. Yoo, H. K. Park, and Y. R. Do, "Analysis of circadian properties and healthy levels of blue light from smartphones at night," Scientific Reports, vol. 5, article 11325, 2015.

[59] A. L. Gamble, A. L. D'Rozario, D. J. Bartlett et al., “Adolescent sleep patterns and night-time technology use: results of the Australian Broadcasting Corporation's Big Sleep Survey," PLoS One, vol. 9, no. 11, article e111700, 2014.

[60] C. S. Nikhita, P. R. Jadhav, and S. A. Ajinkya, "Prevalence of mobile phone dependence in secondary school adolescents," Journal of Clinical and Diagnostic Research, vol. 9, no. 11, pp. VC06-VC09, 2015.

[61] N. L. Bragazzi and G. Del Puente, "A proposal for including nomophobia in the new DSM-V," Psychology Research and Behavior Management, vol. 7, pp. 155-160, 2014.

[62] N. Nathan and J. Zeitzer, "A survey study of the association between mobile phone use and daytime sleepiness in California high school students," BMC Public Health, vol. 13, p. 840, 2013.

[63] S. Sahin, K. Ozdemir, A. Unsal, and N. Temiz, "Evaluation of mobile phone addiction level and sleep quality in university students," Pakistan Journal of Medical Sciences, vol. 29, no. 4, pp. 913-918, 2013.

[64] B. Tassino, S. Horta, N. Santana, R. Levandovski, and A. Silva, "Extreme late chronotypes and social jetlag challenged by Antarctic conditions in a population of university students from Uruguay," Sleep Science, vol. 9, no. 1, pp. 20-28, 2016.
[65] T. Roenneberg, K. V. Allebrandt, M. Merrow, and C. Vetter, "Social jetlag and obesity," Current Biology, vol. 22, no. 10, pp. 939-943, 2012.

[66] F. Rutters, S. G. Lemmens, T. C. Adam et al., "Is social jetlag associated with an adverse endocrine, behavioral, and cardiovascular risk profile?," Journal of Biological Rhythms, vol. 29, no. 5, pp. 377-383, 2014.

[67] P. M. Wong, B. P. Hasler, T. W. Kamarck, M. F. Muldoon, and S. B. Manuck, "Social jetlag, chronotype, and cardiometabolic risk," The Journal of Clinical Endocrinology \& Metabolism, vol. 100, no. 12, pp. 4612-4620, 2015.

[68] R. Levandovski, G. Dantas, L. C. Fernandes et al., "Depression scores associate with chronotype and social jetlag in a rural population," Chronobiology International, vol. 28, no. 9, pp. 771-778, 2011.

[69] D. Landayan and F. W. Wolf, "Shared neurocircuitry underlying feeding and drugs of abuse in Drosophila," Biomedical Journal, vol. 38, no. 6, pp. 496-509, 2015.

[70] A. S. Narayanan and A. Rothenfluh, "I believe I can fly!: use of drosophila as a model organism in neuropsychopharmacology research," Neuropsychopharmacology, vol. 41, no. 6, pp. 1439-1446, 2016.

[71] A. Park, A. Ghezzi, T. P. Wijesekera, and N. S. Atkinson, "Genetics and genomics of alcohol responses in Drosophila," Neuropharmacology, vol. 122, 2017.

[72] S. Fujii, P. Krishnan, P. Hardin, and H. Amrein, "Nocturnal male sex drive in Drosophila," Current Biology, vol. 17, no. 3, pp. 244-251, 2007.

[73] Y. Zhang, Y. Liu, D. Bilodeau-Wentworth, P. E. Hardin, and P. Emery, "Light and temperature control the contribution of specific DN1 neurons to Drosophila circadian behavior," Current Biology, vol. 20, no. 7, pp. 600-605, 2010.

[74] A. V. Devineni and U. Heberlein, "The evolution of Drosophila melanogaster as a model for alcohol research," Annual Review of Neuroscience, vol. 36, pp. 121-138, 2013.

[75] J. H. Jennings, D. Mazzi, M. G. Ritchie, and A. Hoikkala, "Sexual and postmating reproductive isolation between allopatric Drosophila montana populations suggest speciation potential," BMC Evolutionary Biology, vol. 11, p. 68, 2011.

[76] E. Bier, "Drosophila, the golden bug, emerges as a tool for human genetics," Nature Reviews Genetics, vol. 6, no. 1, pp. 9-23, 2005.

[77] R. J. Greenspan and H. A. Dierick, “'Am not I a fly like thee?' from genes in fruit flies to behavior in humans," Human Molecular Genetics, vol. 13, Spec No 2, pp. R267-R273, 2004.

[78] K. G. Hales, C. A. Korey, A. M. Larracuente, and D. M. Roberts, "Genetics on the fly: a primer on the Drosophila model system," Genetics, vol. 201, no. 3, pp. 815-842, 2015.

[79] D. B. Sattelle and S. D. Buckingham, "Invertebrate studies and their ongoing contributions to neuroscience," Invertebrate Neuroscience, vol. 6, no. 1, pp. 1-3, 2006.

[80] K. J. Venken, K. L. Schulze, N. A. Haelterman et al., "MiMIC: a highly versatile transposon insertion resource for engineering Drosophila melanogaster genes," Nature Methods, vol. 8, no. 9, pp. 737-743, 2011.

[81] K. J. Venken, J. H. Simpson, and H. J. Bellen, “Genetic manipulation of genes and cells in the nervous system of the fruit fly," Neuron, vol. 72, no. 2, pp. 202-230, 2011.

[82] Y. He and H. Jasper, "Studying aging in Drosophila," Methods, vol. 68, no. 1, pp. 129-133, 2014. 
[83] A. Bitto, A. M. Wang, C. F. Bennett, and M. Kaeberlein, "Biochemical genetic pathways that modulate aging in multiple species," Cold Spring Harbor Perspectives in Medicine, vol. 5, no. 11, 2015.

[84] Y. Sun, J. Yolitz, C. Wang, E. Spangler, M. Zhan, and S. Zou, "Aging studies in Drosophila melanogaster," Methods in Molecular Biology, vol. 1048, pp. 77-93, 2013.

[85] M. S. Grotewiel, I. Martin, P. Bhandari, and E. Cook-Wiens, "Functional senescence in Drosophila melanogaster," Ageing Research Reviews, vol. 4, no. 3, pp. 372-397, 2005.

[86] E. P. Ratliff, R. E. Mauntz, R. W. Kotzebue et al., "Aging and autophagic function influences the progressive decline of adult Drosophila behaviors," PLoS One, vol. 10, no. 7, article e0132768, 2015.

[87] S. Poddighe, K. M. Bhat, M. D. Setzu et al., "Impaired sense of smell in a Drosophila Parkinson's model," PLoS One, vol. 8, no. 8, article e73156, 2013.

[88] C. Cirelli, "Brain plasticity, sleep and aging," Gerontology, vol. 58, no. 5, pp. 441-5, 2012.

[89] G. Cornelissen and K. Otsuka, "Chronobiology of aging: a mini-review," Gerontology, vol. 63, no. 2, pp. 118-128, 2017.

[90] K. Rakshit, N. Krishnan, E. M. Guzik, E. Pyza, and J. M. Giebultowicz, "Effects of aging on the molecular circadian oscillations in Drosophila," Chronobiology International, vol. 29, no. 1, pp. 5-14, 2012.

[91] M. Robertson and A. C. Keene, "Molecular mechanisms of age-related sleep loss in the fruit fly - a mini-review," Gerontology, vol. 59, no. 4, pp. 334-339, 2013.

[92] A. Vaccaro, S. Birman, and A. Klarsfeld, "Chronic jet lag impairs startle-induced locomotion in Drosophila," Experimental Gerontology, vol. 85, pp. 24-27, 2016.

[93] M. Saitoe, J. Horiuchi, T. Tamura, and N. Ito, "Drosophila as a novel animal model for studying the genetics of age-related memory impairment," Reviews in the Neurosciences, vol. 16, no. 2, pp. 137-149, 2005.

[94] D. Yamazaki and M. Saitoe, "cAMP/PKA signaling underlies age-related memory impairment," Brain and Nerve, vol. 60, no. 7, pp. 717-724, 2008.

[95] T. Kudo, M. Uchigashima, T. Miyazaki et al., "Three types of neurochemical projection from the bed nucleus of the stria terminalis to the ventral tegmental area in adult mice," Journal of Neuroscience, vol. 32, no. 50, pp. 18035-18046, 2012.

[96] A. Beramendi, S. Peron, G. Casanova, C. Reggiani, and R. Cantera, "Neuromuscular junction in abdominal muscles of Drosophila melanogaster during adulthood and aging," The Journal of Comparative Neurology, vol. 501, no. 4, pp. 498-508, 2007.

[97] N. Krishnan, K. Rakshit, E. S. Chow, J. S. Wentzell, D. Kretzschmar, and J. M. Giebultowicz, "Loss of circadian clock accelerates aging in neurodegeneration-prone mutants," Neurobiology of Disease, vol. 45, no. 3, pp. 11291135, 2012.

[98] M. S. Miller, P. Lekkas, J. M. Braddock et al., “Aging enhances indirect flight muscle fiber performance yet decreases flight ability in Drosophila," Biophysical Journal, vol. 95, no. 5, pp. 2391-2401, 2008.

[99] S. M. Egenriether, E. S. Chow, N. Krauth, and J. M. Giebultowicz, "Accelerated food source location in aging Drosophila," Aging Cell, vol. 14, no. 5, pp. 916-918, 2015.

[100] I. Eleftherianos and J. C. Castillo, "Molecular mechanisms of aging and immune system regulation in Drosophila,"
International Journal of Molecular Sciences, vol. 13, no. 8, pp. 9826-9844, 2012.

[101] K. Ocorr, L. Perrin, H. Y. Lim, L. Qian, X. Wu, and R. Bodmer, "Genetic control of heart function and aging in Drosophila," Trends in Cardiovascular Medicine, vol. 17, no. 5, pp. 177-182, 2007.

[102] S. C. Pandey, "Neuronal signaling systems and ethanol dependence," Molecular Neurobiology, vol. 17, no. 1-3, pp. 1-15, 1998.

[103] U. B. Pandey and C. D. Nichols, "Human disease models in Drosophila melanogaster and the role of the fly in therapeutic drug discovery," Pharmacological Reviews, vol. 63, no. 2, pp. 411-436, 2011.

[104] M. D. Adams, S. E. Celniker, R. A. Holt et al., "The genome sequence of Drosophila melanogaster," Science, vol. 287, no. 5461, pp. 2185-2195, 2000.

[105] T. E. Lloyd and J. P. Taylor, "Flightless flies: Drosophila models of neuromuscular disease," Annals of the New York Academy of Sciences, vol. 1184, pp. e1-20, 2010.

[106] L. T. Reiter, L. Potocki, S. Chien, M. Gribskov, and E. Bier, “A systematic analysis of human disease-associated gene sequences in Drosophila melanogaster," Genome Research, vol. 11, no. 6, pp. 1114-1125, 2001.

[107] R. Brandt and A. Paululat, "Microcompartments in the Drosophila heart and the mammalian brain: general features and common principles," Biological Chemistry, vol. 394, no. 2, pp. 217-230, 2013.

[108] L. Ma, "Can the Drosophila model help in paving the way for translational medicine in heart failure?," Biochemical Society Transactions, vol. 44, no. 5, pp. 1549-1560, 2016.

[109] D. Seyres, L. Röder, and L. Perrin, "Genes and networks regulating cardiac development and function in flies: genetic and functional genomic approaches," Briefings in Functional Genomics, vol. 11, no. 5, pp. 366-374, 2012.

[110] T. Roeder, K. Isermann, K. Kallsen, K. Uliczka, and C. Wagner, "A Drosophila asthma model - what the fly tells us about inflammatory diseases of the lung," Advances in Experimental Medicine and Biology, vol. 710, pp. 37-47, 2012.

[111] L. Zuo, E. Iordanou, R. R. Chandran, and L. Jiang, "Novel mechanisms of tube-size regulation revealed by the Drosophila trachea," Cell and Tissue Research, vol. 354, no. 2, pp. 343-354, 2013.

[112] J. A. Dow and M. F. Romero, "Drosophila provides rapid modeling of renal development, function, and disease," American Journal of Physiology - Renal Physiology, vol. 299, no. 6, pp. F1237-F1244, 2010.

[113] J. Miller, T. Chi, P. Kapahi et al., "Drosophila melanogaster as an emerging translational model of human nephrolithiasis," The Journal of Urology, vol. 190, no. 5, pp. 1648-1656, 2013.

[114] B. Erkosar and F. Leulier, "Transient adult microbiota, gut homeostasis and longevity: novel insights from the Drosophila model," FEBS Letters, vol. 588, no. 22, pp. 4250-4257, 2014.

[115] R. J. Katzenberger, B. Ganetzky, and D. A. Wassarman, "The gut reaction to traumatic brain injury," Fly, vol. 9, no. 2, pp. 68-74, 2015.

[116] M. Y. Pasco, R. Loudhaief, and A. Gallet, "The cellular homeostasis of the gut: what the Drosophila model points out," Histology and Histopathology, vol. 30, no. 3, pp. 277292, 2015. 
[117] J. M. McLaughlin and D. P. Bratu, "Drosophila melanogaster oogenesis: an overview," Methods in Molecular Biology, vol. 1328, pp. 1-20, 2015.

[118] N. A. Siddall and G. R. Hime, "A Drosophila toolkit for defining gene function in spermatogenesis," Reproduction, vol. 153, no. 4, pp. R121-R132, 2017.

[119] H. Kazama, "Systems neuroscience in Drosophila: conceptual and technical advantages," Neuroscience, vol. 296, pp. 3-14, 2015.

[120] C. Maximino, R. X. Silva, N. da Silva Sde et al., "Nonmammalian models in behavioral neuroscience: consequences for biological psychiatry," Frontiers in Behavioral Neuroscience, vol. 9, p. 233, 2015.

[121] G. Artiushin and A. Sehgal, "The Drosophila circuitry of sleep-wake regulation," Current Opinion in Neurobiology, vol. 44, pp. 243-250, 2017.

[122] K. M. Parisky, J. L. Agosto Rivera, N. C. Donelson, S. Kotecha, and L. C. Griffith, "Reorganization of sleep by temperature in drosophila requires light, the homeostat, and the circadian clock," Current Biology, vol. 26, no. 7, pp. 882-892, 2016.

[123] S. Potdar and V. Sheeba, "Lessons from sleeping flies: insights from Drosophila melanogaster on the neuronal circuitry and importance of sleep," Journal of Neurogenetics, vol. 27, no. 1-2, pp. 23-42, 2013.

[124] G. U. Busto, T. Guven-Ozkan, and R. L. Davis, "MicroRNA function in Drosophila memory formation," Current Opinion in Neurobiology, vol. 43, pp. 15-24, 2016.

[125] K. R. Kaun and A. Rothenfluh, "Dopaminergic rules of engagement for memory in Drosophila," Current Opinion in Neurobiology, vol. 43, pp. 56-62, 2017.

[126] A. French, M. Ali Agha, A. Mitra, A. Yanagawa, M. J. Sellier, and F. Marion-Poll, "Drosophila bitter taste(s)," Frontiers in Integrative Neuroscience, vol. 9, p. 58, 2015.

[127] A. S. French, M. J. Sellier, M. Ali Agha et al., "Dual mechanism for bitter avoidance in Drosophila," Journal of Neuroscience, vol. 35, no. 9, pp. 3990-4004, 2015.

[128] R. M. Joseph and J. R. Carlson, "Drosophila chemoreceptors: a molecular interface between the chemical world and the brain," Trends in Genetics, vol. 31, no. 12, pp. 683-695, 2015.

[129] C. Melcher, R. Bader, and M. J. Pankratz, "Amino acids, taste circuits, and feeding behavior in Drosophila: towards understanding the psychology of feeding in flies and man," Journal of Endocrinology, vol. 192, no. 3, pp. 467-472, 2007.

[130] E. J. Beckwith and M. F. Ceriani, "Communication between circadian clusters: the key to a plastic network," FEBS Letters, vol. 589, no. 22, pp. 3336-3342, 2015.

[131] E. J. Beckwith and M. F. Ceriani, "Experimental assessment of the network properties of the Drosophila circadian clock," Journal of Comparative Neurology, vol. 523, no. 6, pp. 982996, 2015.

[132] C. Helfrich-Förster, "From neurogenetic studies in the fly brain to a concept in circadian biology," Journal of Neurogenetics, vol. 28, no. 3-4, pp. 329-347, 2014.

[133] C. Helfrich-Förster, M. Stengl, and U. Homberg, "Organization of the circadian system in insects," Chronobiology International, vol. 15, no. 6, pp. 567-594, 1998.

[134] O. Tataroglu and P. Emery, "Studying circadian rhythms in Drosophila melanogaster," Methods, vol. 68, no. 1, pp. 140150, 2014.
[135] E. D. Hoopfer, "Neural control of aggression in Drosophila," Current Opinion in Neurobiology, vol. 38, pp. 109-118, 2016.

[136] E. A. Kravitz and L. Fernandez Mde, "Aggression in Drosophila," Behavioral Neuroscience, vol. 129, no. 5, pp. 549563, 2015.

[137] D. Yamamoto and K. Sato, "The female brain and the male brain," Brain and Nerve, vol. 65, no. 10, pp. 1147-1158, 2013.

[138] D. Yamamoto, K. Sato, and M. Koganezawa, "Neuroethology of male courtship in Drosophila: from the gene to behavior," Journal of Comparative Physiology A, vol. 200, no. 4, pp. 251264, 2014.

[139] K. R. Kaun, A. V. Devineni, and U. Heberlein, "Drosophila melanogaster as a model to study drug addiction," Human Genetics, vol. 131, no. 6, pp. 959-975, 2012.

[140] J. T. Littleton and B. Ganetzky, "Ion channels and synaptic organization: analysis of the Drosophila genome," Neuron, vol. 26, no. 1, pp. 35-43, 2000.

[141] C. A. Martin and D. E. Krantz, "Drosophila melanogaster as a genetic model system to study neurotransmitter transporters," Neurochemistry International, vol. 73, pp. 71-88, 2014.

[142] D. R. Nässel and A. M. Winther, "Drosophila neuropeptides in regulation of physiology and behavior," Progress in Neurobiology, vol. 92, no. 1, pp. 42-104, 2010.

[143] R. J. Konopka, C. Pittendrigh, and D. Orr, "Reciprocal behaviour associated with altered homeostasis and photosensitivity of Drosophila clock mutants," Journal of Neurogenetics, vol. 6, no. 1, pp. 1-10, 1989.

[144] C. S. Pittendrigh, P. C. Caldarola, and E. S. Cosbey, "A differential effect of heavy water on temperature-dependent and temperature-compensated aspects of circadian system of Drosophila pseudoobscura," Proceedings of the National Academy of Sciences of the United States of America, vol. 70, no. 7, pp. 2037-2041, 1973.

[145] C. S. Pittendrigh, W. T. Kyner, and T. Takamura, “The amplitude of circadian oscillations: temperature dependence, latitudinal clines, and the photoperiodic time measurement," Journal of Biological Rhythms, vol. 6, no. 4, pp. 299-313, 1991.

[146] C. S. Pittendrigh and D. H. Minis, "Circadian systems: longevity as a function of circadian resonance in Drosophila melanogaster," Proceedings of the National Academy of Sciences of the United States of America, vol. 69, no. 6, pp. 1537-1539, 1972.

[147] C. S. Pittendrigh and T. Takamura, "Latitudinal clines in the properties of a circadian pacemaker," Journal of Biological Rhythms, vol. 4, no. 2, pp. 217-235, 1989.

[148] Y. Zhang, J. Ling, C. Yuan, R. Dubruille, and P. Emery, “A role for Drosophila ATX2 in activation of PER translation and circadian behavior," Science, vol. 340, no. 6134, pp. 879-882, 2013.

[149] Y. Zhang and P. Emery, "GW182 controls Drosophila circadian behavior and PDF-receptor signaling," Neuron, vol. 78, no. 1, pp. 152-165, 2013.

[150] L. C. Lyons and G. Roman, "Circadian modulation of shortterm memory in Drosophila," Learning \& Memory, vol. 16, no. 1, pp. 19-27, 2009.

[151] F. Guo, J. Yu, H. J. Jung et al., "Circadian neuron feedback controls the Drosophila sleep-activity profile," Nature, vol. 536, no. 7616, pp. 292-297, 2016.

[152] R. Allada and B. Y. Chung, "Circadian organization of behavior and physiology in Drosophila," Annual Review of Physiology, vol. 72, pp. 605-624, 2010. 
[153] J. Tomita, G. Ban, and K. Kume, "Genes and neural circuits for sleep of the fruit fly," Neuroscience Research, vol. 118, pp. 82-91, 2017.

[154] Y. Hamasaka, T. Suzuki, S. Hanai, and N. Ishida, "Evening circadian oscillator as the primary determinant of rhythmic motivation for Drosophila courtship behavior," Genes to Cells, vol. 15, no. 12, pp. 1240-1248, 2010.

[155] I. Medina, J. Casal, and C. C. Fabre, "Do circadian genes and ambient temperature affect substrate-borne signalling during Drosophila courtship?," Biology Open, vol. 4, no. 11, pp. 1549-1557, 2015.

[156] H. C. Krishnan and L. C. Lyons, "Synchrony and desynchrony in circadian clocks: impacts on learning and memory," Learning \& Memory, vol. 22, no. 9, pp. 426-437, 2015.

[157] J. E. Lee and I. Edery, "Circadian regulation in the ability of Drosophila to combat pathogenic infections," Current Biology, vol. 18, no. 3, pp. 195-199, 2008.

[158] A. Chatterjee and P. E. Hardin, "Time to taste: circadian clock function in the Drosophila gustatory system," Fly, vol. 4, no. 4, pp. 283-287, 2010.

[159] A. Chatterjee, S. Tanoue, J. H. Houl, and P. E. Hardin, "Regulation of gustatory physiology and appetitive behavior by the Drosophila circadian clock," Current Biology, vol. 20, no. 4, pp. 300-309, 2010.

[160] N. Krishnan, D. Kretzschmar, K. Rakshit, E. Chow, and J. M. Giebultowicz, "The circadian clock gene period extends healthspan in aging Drosophila melanogaster," Aging, vol. 1, no. 11, pp. 937-948, 2009.

[161] P. Karpowicz, Y. Zhang, J. B. Hogenesch, P. Emery, and N. Perrimon, "The circadian clock gates the intestinal stem cell regenerative state," Cell Reports, vol. 3, no. 4, pp. 9961004,2013

[162] R. J. Konopka and S. Benzer, "Clock mutants of Drosophila melanogaster," Proceedings of the National Academy of Sciences of the United States of America, vol. 68, no. 9, pp. 2112-2116, 1971.

[163] J. Y. Fan, B. Agyekum, A. Venkatesan et al., "Noncanonical FK506-binding protein BDBT binds DBT to enhance its circadian function and forms foci at night," Neuron, vol. 80, no. 4, pp. 984-996, 2013.

[164] J. M. Lin, V. L. Kilman, K. Keegan et al., "A role for casein kinase $2 \alpha$ in the Drosophila circadian clock," Nature, vol. 420, no. 6917, pp. 816-820, 2002.

[165] J. L. Price, J. Blau, A. Rothenfluh, M. Abodeely, B. Kloss, and M. W. Young, "double-time is a novel Drosophila clock gene that regulates PERIOD protein accumulation," Cell, vol. 94, no. 1, pp. 83-95, 1998.

[166] S. M. Reppert and I. Sauman, "period and timeless tango: a dance of two clock genes," Neuron, vol. 15, no. 5, pp. 983986, 1995.

[167] A. Sehgal, J. L. Price, B. Man, and M. W. Young, "Loss of circadian behavioral rhythms and per RNA oscillations in the Drosophila mutant timeless," Science, vol. 263, no. 5153, pp. 1603-1606, 1994.

[168] R. Allada, N. E. White, W. V. So, J. C. Hall, and M. Rosbash, "A mutant Drosophila homolog of mammalian Clock disrupts circadian rhythms and transcription of period and timeless," Cell, vol. 93, no. 5, pp. 791-804, 1998.

[169] B. Akten, E. Jauch, G. K. Genova et al., "A role for CK2 in the Drosophila circadian oscillator," Nature Neuroscience, vol. 6, no. 3, pp. 251-257, 2003.
[170] S. Martinek, S. Inonog, A. S. Manoukian, and M. W. Young, "A role for the segment polarity gene shaggy/GSK-3 in the Drosophila circadian clock," Cell, vol. 105, no. 6, pp. 769-779, 2001.

[171] J. E. Rutila, V. Suri, M. Le, W. V. So, M. Rosbash, and J. C. Hall, "CYCLE is a second bHLH-PAS clock protein essential for circadian rhythmicity and transcription of Drosophila period and timeless," Cell, vol. 93, no. 5, pp. 805-814, 1998.

[172] B. Kloss, J. L. Price, L. Saez et al., “The Drosophila clock gene double-time encodes a protein closely related to human casein kinase IE," Cell, vol. 94, no. 1, pp. 97-107, 1998.

[173] H. Tei, H. Okamura, Y. Shigeyoshi et al., "Circadian oscillation of a mammalian homologue of the Drosophila period gene," Nature, vol. 389, no. 6650, pp. 512-516, 1997.

[174] D. P. King, Y. Zhao, A. M. Sangoram et al., "Positional cloning of the mouse circadian clock gene," Cell, vol. 89, no. 4, pp. 641-653, 1997.

[175] M. P. Antoch, E. J. Song, A. M. Chang et al., "Functional identification of the mouse circadian Clock gene by transgenic BAC rescue," Cell, vol. 89, no. 4, pp. 655-667, 1997.

[176] T. Yoshii, C. Hermann-Luibl, and C. Helfrich-Förster, "Circadian light-input pathways in Drosophila," Communicative \& Integrative Biology, vol. 9, no. 1, article e1102805, 2016.

[177] Z. Yao and O. T. Shafer, "The Drosophila circadian clock is a variably coupled network of multiple peptidergic units," Science, vol. 343, no. 6178, pp. 1516-1520, 2014.

[178] P. E. Hardin and S. Panda, "Circadian timekeeping and output mechanisms in animals," Current Opinion in Neurobiology, vol. 23, no. 5, pp. 724-731, 2013.

[179] O. Ozkaya and E. Rosato, "Chapter 4 - the circadian clock of the fly: a neurogenetics journey through time," Advances in Genetics, vol. 77, pp. 79-123, 2012.

[180] C. Dibner, U. Schibler, and U. Albrecht, "The mammalian circadian timing system: organization and coordination of central and peripheral clocks," Annual Review of Physiology, vol. 72, pp. 517-549, 2010.

[181] C. H. Ko and J. S. Takahashi, "Molecular components of the mammalian circadian clock," Human Molecular Genetics, vol. 15, Spec No 2, pp. R271-R277, 2006.

[182] N. R. Glossop, L. C. Lyons, and P. E. Hardin, "Interlocked feedback loops within the Drosophila circadian oscillator," Science, vol. 286, no. 5440, pp. 766-768, 1999.

[183] P. E. Hardin, J. C. Hall, and M. Rosbash, "Circadian oscillations in period gene mRNA levels are transcriptionally regulated," Proceedings of the National Academy of Sciences of the United States of America, vol. 89, no. 24, pp. 1171111715, 1992.

[184] C. Dubowy and A. Sehgal, "Circadian rhythms and sleep in Drosophila melanogaster," Genetics, vol. 205, no. 4, pp. 1373-1397, 2017.

[185] S. Panda, "Circadian physiology of metabolism," Science, vol. 354, no. 6315 , pp. 1008-1015, 2016.

[186] J. S. Takahashi, "Transcriptional architecture of the mammalian circadian clock," Nature Reviews Genetics, vol. 18, no. 3, pp. 164-179, 2017.

[187] J. S. Menet, K. C. Abruzzi, J. Desrochers, J. Rodriguez, and M. Rosbash, "Dynamic PER repression mechanisms in the Drosophila circadian clock: from on-DNA to off-DNA," Genes \& Development, vol. 24, no. 4, pp. 358-367, 2010.

[188] K. C. Abruzzi, J. Rodriguez, J. S. Menet et al., "Drosophila CLOCK target gene characterization: implications for 
circadian tissue-specific gene expression," Genes \& Development, vol. 25, no. 22, pp. 2374-2386, 2011.

[189] Q. He, B. Wu, J. L. Price, and Z. Zhao, "Circadian rhythm neuropeptides in Drosophila: signals for normal circadian function and circadian neurodegenerative disease," International Journal of Molecular Sciences, vol. 18, no. 4, 2017.

[190] N. Huang, Y. Chelliah, Y. Shan et al., "Crystal structure of the heterodimeric CLOCK:BMAL1 transcriptional activator complex," Science, vol. 337, no. 6091, pp. 189-194, 2012.

[191] C. L. Partch, C. B. Green, and J. S. Takahashi, "Molecular architecture of the mammalian circadian clock," Trends in Cell Biology, vol. 24, no. 2, pp. 90-99, 2014.

[192] H. W. Ko, E. Y. Kim, J. Chiu, J. T. Vanselow, A. Kramer, and I. Edery, "A hierarchical phosphorylation cascade that regulates the timing of PERIOD nuclear entry reveals novel roles for proline-directed kinases and GSK-3 $\beta /$ SGG in circadian clocks," Journal of Neuroscience, vol. 30, no. 38, pp. 12664-12675, 2010.

[193] C. Iitaka, K. Miyazaki, T. Akaike, and N. Ishida, "A role for glycogen synthase kinase- $3 \beta$ in the mammalian circadian clock," Journal of Biological Chemistry, vol. 280, no. 33, pp. 29397-29402, 2005.

[194] O. Tataroglu and P. Emery, "The molecular ticks of the Drosophila circadian clock," Current Opinion in Insect Science, vol. 7, pp. 51-57, 2015.

[195] A. B. Corl, K. H. Berger, G. Ophir-Shohat et al., "Happyhour, a Ste20 family kinase, implicates EGFR signaling in ethanol-induced behaviors," Cell, vol. 137, no. 5, pp. 949960, 2009.

[196] D. Kapfhamer, S. Taylor, M. E. Zou, J. P. Lim, V. Kharazia, and U. Heberlein, "Taok2 controls behavioral response to ethanol in mice," Genes, Brain, and Behavior, vol. 12, no. 1, pp. 87-97, 2013.

[197] H. Scholz and J. A. Mustard, "Invertebrate models of alcoholism," Current Topics in Behavioral Neurosciences, vol. 13, pp. 433-457, 2013.

[198] A. V. Devineni and U. Heberlein, "Preferential ethanol consumption in Drosophila models features of addiction," Current Biology, vol. 19, no. 24, pp. 2126-2132, 2009.

[199] A. R. Rodan and A. Rothenfluh, "The genetics of behavioral alcohol responses in Drosophila," International Review of Neurobiology, vol. 91, pp. 25-51, 2010.

[200] K. R. Kaun, R. Azanchi, Z. Maung, J. Hirsh, and U. Heberlein, "A Drosophila model for alcohol reward," Nature Neuroscience, vol. 14, no. 5, pp. 612-619, 2011.

[201] A. V. Devineni and U. Heberlein, "Acute ethanol responses in Drosophila are sexually dimorphic," Proceedings of the National Academy of Sciences of the United States of America, vol. 109, no. 51, pp. 21087-21092, 2012.

[202] A. K. De Nobrega and L. C. Lyons, "Circadian modulation of alcohol-induced sedation and recovery in male and female Drosophila," Journal of Biological Rhythms, vol. 31, no. 2, pp. 142-160, 2016.

[203] A. V. Devineni, K. D. McClure, D. J. Guarnieri et al., "The genetic relationships between ethanol preference, acute ethanol sensitivity, and ethanol tolerance in Drosophila melanogaster," Fly, vol. 5, no. 3, pp. 191-199, 2011.

[204] K. H. Berger, U. Heberlein, and M. S. Moore, "Rapid and chronic: two distinct forms of ethanol tolerance in Drosophila," Alcoholism, Clinical and Experimental Research, vol. 28, no. 10, pp. 1469-1480, 2004.
[205] H. Scholz, J. Ramond, C. M. Singh, and U. Heberlein, "Functional ethanol tolerance in Drosophila," Neuron, vol. 28, no. 1, pp. 261-271, 2000.

[206] H. R. Krishnan, X. Li, A. Ghezzi, and N. S. Atkinson, “A DNA element in the slo gene modulates ethanol tolerance," Alcohol, vol. 51, pp. 37-42, 2016.

[207] W. W. Ja, G. B. Carvalho, E. M. Mak et al., "Prandiology of Drosophila and the CAFE assay," Proceedings of the National Academy of Sciences of the United States of America, vol. 104, no. 20, pp. 8253-8256, 2007.

[208] A. V. Devineni and U. Heberlein, "Addiction-like behavior in Drosophila," Communicative \& Integrative Biology, vol. 3, no. 4, pp. 357-359, 2010.

[209] S. Xu, T. Chan, V. Shah, S. Zhang, S. D. Pletcher, and G. Roman, "The propensity for consuming ethanol in Drosophila requires rutabaga adenylyl cyclase expression within mushroom body neurons," Genes, Brain, and Behavior, vol. 11, no. 6, pp. 727-739, 2012.

[210] J. B. Pohl, B. A. Baldwin, B. L. Dinh et al., "Ethanol preference in Drosophila melanogaster is driven by its caloric value," Alcoholism, Clinical and Experimental Research, vol. 36, no. 11, pp. 1903-1912, 2012.

[211] R. L. Peru Y Colón de Portugal, S. A. Ojelade, P. S. Penninti et al., "Long-lasting, experience-dependent alcohol preference in Drosophila," Addiction Biology, vol. 19, no. 3, pp. 392-401, 2014.

[212] D. J. Guarnieri and U. Heberlein, "Drosophila melanogaster, a genetic model system for alcohol research," International Review of Neurobiology, vol. 54, pp. 199-228, 2003.

[213] L. Sivanantharajah and B. Zhang, "Current techniques for high-resolution mapping of behavioral circuits in Drosophila," Journal of Comparative Physiology A, vol. 201, no. 9, pp. 895-909, 2015.

[214] D. M. Lovinger, G. White, and F. F. Weight, "Ethanol inhibits NMDA-activated ion current in hippocampal neurons," Science, vol. 243, no. 4899, pp. 1721-1724, 1989.

[215] M. Roberto and F. P. Varodayan, "Synaptic targets: chronic alcohol actions," Neuropharmacology, vol. 122, pp. 85-99, 2017.

[216] M. S. Moore, J. DeZazzo, A. Y. Luk, T. Tully, C. M. Singh, and U. Heberlein, "Ethanol intoxication in Drosophila: genetic and pharmacological evidence for regulation by the cAMP signaling pathway," Cell, vol. 93, no. 6, pp. 997-1007, 1998.

[217] S. K. Park, S. A. Sedore, C. Cronmiller, and J. Hirsh, “Type II cAMP-dependent protein kinase-deficient Drosophila are viable but show developmental, circadian, and drug response phenotypes," Journal of Biological Chemistry, vol. 275, no. 27, pp. 20588-20596, 2000.

[218] G. Wand, M. Levine, L. Zweifel, W. Schwindinger, and T. Abel, "The cAMP-protein kinase A signal transduction pathway modulates ethanol consumption and sedative effects of ethanol," Journal of Neuroscience, vol. 21, no. 14, pp. 52975303, 2001.

[219] T. E. Thiele, B. Willis, J. Stadler, J. G. Reynolds, I. L. Bernstein, and G. S. McKnight, "High ethanol consumption and low sensitivity to ethanol-induced sedation in protein kinase Amutant mice," Journal of Neuroscience, vol. 20, no. 10, article RC75, 2000.

[220] M. B. Feany and W. G. Quinn, "A neuropeptide gene defined by the Drosophila memory mutant amnesiac," Science, vol. 268, no. 5212, pp. 869-873, 1995. 
[221] A. W. Lasek, F. Giorgetti, K. H. Berger, S. Tayor, and U. Heberlein, "Lmo genes regulate behavioral responses to ethanol in Drosophila melanogaster and the mouse," Alcoholism, Clinical and Experimental Research, vol. 35, no. 9, pp. 1600-1606, 2011.

[222] A. Savarese, M. E. Zou, V. Kharazia, R. Maiya, and A. W. Lasek, "Increased behavioral responses to ethanol in $\mathrm{Lmo3}$ knockout mice," Genes, Brain, and Behavior, vol. 13, no. 8, pp. 777-783, 2014.

[223] A. W. Lasek, J. Lim, C. L. Kliethermes et al., “An evolutionary conserved role for anaplastic lymphoma kinase in behavioral responses to ethanol," PLoS One, vol. 6, no. 7, article e22636, 2011.

[224] J. Y. Gouzi, A. Moressis, J. A. Walker et al., "The receptor tyrosine kinase Alk controls neurofibromin functions in Drosophila growth and learning," PLoS Genetics, vol. 7, no. 9, article e1002281, 2011.

[225] J. W. Dutton, H. Chen, C. You, M. S. Brodie, and A. W. Lasek, "Anaplastic lymphoma kinase regulates binge-like drinking and dopamine receptor sensitivity in the ventral tegmental area," Addiction Biology, vol. 22, no. 3, pp. 665-678, 2017.

[226] P. Schweitzer, C. Cates-Gatto, F. P. Varodayan et al., "Dependence-induced ethanol drinking and GABA neurotransmission are altered in Alk deficient mice," Neuropharmacology, vol. 107, pp. 1-8, 2016.

[227] J. Wang, W. Yuan, and M. D. Li, "Genes and pathways coassociated with the exposure to multiple drugs of abuse, including alcohol, amphetamine/methamphetamine, cocaine, marijuana, morphine, and/or nicotine: a review of proteomics analyses," Molecular Neurobiology, vol. 44, no. 3, pp. 269286, 2011.

[228] S. Dzitoyeva, N. Dimitrijevic, and H. Manev, " $\gamma$-Aminobutyric acid B receptor 1 mediates behavior-impairing actions of alcohol in Drosophila: adult RNA interference and pharmacological evidence," Proceedings of the National Academy of Sciences of the United States of America, vol. 100, no. 9, pp. 5485-5490, 2003.

[229] M. J. Zaleski, J. R. Nunes Filho, T. Lemos, and G. S. Morato, " $\mathrm{GABA}_{\mathrm{B}}$ receptors play a role in the development of tolerance to ethanol in mice," Psychopharmacology, vol. 153, no. 4, pp. 415-424, 2001.

[230] M. S. Dar, "Mouse cerebellar GABA B $_{B}$ participation in the expression of acute ethanol-induced ataxia and in its modulation by the cerebellar adenosinergic $\mathrm{A}_{1}$ system," Brain Research Bulletin, vol. 41, no. 1, pp. 53-59, 1996.

[231] B. M. Walker and G. F. Koob, “The $\gamma$-aminobutyric acid-B receptor agonist baclofen attenuates responding for ethanol in ethanol-dependent rats," Alcoholism, Clinical and Experimental Research, vol. 31, no. 1, pp. 11-18, 2007.

[232] J. Besheer, V. Lepoutre, and C. W. Hodge, "GABA B $_{\text {receptor }}$ agonists reduce operant ethanol self-administration and enhance ethanol sedation in C57BL/6J mice," Psychopharmacology, vol. 174, no. 3, pp. 358-366, 2004.

[233] E. M. Moore, K. M. Serio, K. J. Goldfarb, S. Stepanovska, D. N. Linsenbardt, and S. L. Boehm, "GABAergic modulation of binge-like ethanol intake in C57BL/6J mice," Pharmacology, Biochemistry, and Behavior, vol. 88, no. 1, pp. 105-113, 2007.

[234] C. L. Czachowski, B. H. Legg, and K. H. Stansfield, “Ethanol and sucrose seeking and consumption following repeated administration of the $\mathrm{GABA}_{\mathrm{B}}$ agonist baclofen in rats,"
Alcoholism, Clinical and Experimental Research, vol. 30, no. 5, pp. 812-818, 2006.

[235] C. R. Kasten, S. N. Blasingame, and S. L. Boehm, "Bidirectional enantioselective effects of the $\mathrm{GABA}_{\mathrm{B}}$ receptor agonist baclofen in two mouse models of excessive ethanol consumption," Alcohol, vol. 49, no. 1, pp. 37-46, 2015.

[236] G. Addolorato, F. Caputo, E. Capristo et al., "Baclofen efficacy in reducing alcohol craving and intake: a preliminary doubleblind randomized controlled study," Alcohol and Alcoholism, vol. 37, no. 5, pp. 504-508, 2002.

[237] G. Addolorato, F. Caputo, E. Capristo et al., "Rapid suppression of alcohol withdrawal syndrome by baclofen," The American Journal of Medicine, vol. 112, no. 3, pp. 226-229, 2002.

[238] A. Mirijello, F. Caputo, G. Vassallo et al., "GABAB agonists for the treatment of alcohol use disorder," Current Pharmaceutical Design, vol. 21, no. 23, pp. 3367-3372, 2015.

[239] A. Mirijello, C. D'Angelo, A. Ferrulli et al., "Identification and management of alcohol withdrawal syndrome," Drugs, vol. 75, no. 4, pp. 353-365, 2015.

[240] L. Leggio, W. H. Zywiak, J. E. McGeary et al., "A human laboratory pilot study with baclofen in alcoholic individuals," Pharmacology, Biochemistry, and Behavior, vol. 103, no. 4, pp. 784-791, 2013.

[241] N. L. Urizar, Z. Yang, H. J. Edenberg, and R. L. Davis, "Drosophila homer is required in a small set of neurons including the ellipsoid body for normal ethanol sensitivity and tolerance," Journal of Neuroscience, vol. 27, no. 17, pp. 4541-4551, 2007.

[242] K. K. Szumlinski, K. D. Lominac, E. B. Oleson et al., "Homer2 is necessary for EtOH-induced neuroplasticity," Journal of Neuroscience, vol. 25, no. 30, pp. 7054-7061, 2005.

[243] A. Haider, N. C. Woodward, K. D. Lominac et al., "Homer2 within the nucleus accumbens core bidirectionally regulates alcohol intake by both $\mathrm{P}$ and Wistar rats," Alcohol, vol. 49, no. 6, pp. 533-542, 2015.

[244] I. Obara, R. L. Bell, S. P. Goulding et al., "Differential effects of chronic ethanol consumption and withdrawal on homer/glutamate receptor expression in subregions of the accumbens and amygdala of $\mathrm{P}$ rats," Alcoholism, Clinical and Experimental Research, vol. 33, no. 11, pp. 1924-1934, 2009.

[245] R. B. Cowmeadow, H. R. Krishnan, A. Ghezzi, Y. M. Al'Hasan, Y. Z. Wang, and N. S. Atkinson, "Ethanol tolerance caused by slowpoke induction in Drosophila," Alcoholism, Clinical and Experimental Research, vol. 30, no. 5, pp. 745-753, 2006.

[246] A. Ghezzi, Y. M. Al-Hasan, L. E. Larios, R. A. Bohm, and N. S. Atkinson, "slo $\mathrm{K}^{+}$channel gene regulation mediates rapid drug tolerance," Proceedings of the National Academy of Sciences of the United States of America, vol. 101, no. 49, pp. 17276-17281, 2004.

[247] N. S. Atkinson, "Tolerance in Drosophila," Journal of Neurogenetics, vol. 23, no. 3, pp. 293-302, 2009.

[248] R. B. Cowmeadow, H. R. Krishnan, and N. S. Atkinson, "The slowpoke gene is necessary for rapid ethanol tolerance in Drosophila," Alcoholism, Clinical and Experimental Research, vol. 29, no. 10, pp. 1777-1786, 2005.

[249] S. N. Treistman and G. E. Martin, "BK channels: mediators and models for alcohol tolerance," Trends in Neurosciences, vol. 32, no. 12, pp. 629-637, 2009.

[250] P. M. Wynne, S. I. Puig, G. E. Martin, and S. N. Treistman, "Compartmentalized $\beta$ subunit distribution determines 
characteristics and ethanol sensitivity of somatic, dendritic, and terminal large-conductance calcium-activated potassium channels in the rat central nervous system," Journal of Pharmacology and Experimental Therapeutics, vol. 329, no. 3, pp. 978-986, 2009.

[251] B. D. Kyle and A. P. Braun, "The regulation of BK channel activity by pre- and post-translational modifications," Frontiers in Physiology, vol. 5, p. 316, 2014.

[252] A. Z. Pietrzykowski, R. M. Friesen, G. E. Martin et al., "Posttranscriptional regulation of BK channel splice variant stability by miR-9 underlies neuroadaptation to alcohol," Neuron, vol. 59, no. 2, pp. 274-287, 2008.

[253] P. Orio and R. Latorre, "Differential effects of $\beta 1$ and $\beta 2$ subunits on BK channel activity," The Journal of General Physiology, vol. 125, no. 4, pp. 395-411, 2005.

[254] P. Orio, P. Rojas, G. Ferreira, and R. Latorre, "New disguises for an old channel: MaxiK channel $\beta$ subunits," News in Physiological Sciences, vol. 17, pp. 156-161, 2002.

[255] P. L. Feinberg-Zadek and S. N. Treistman, "Beta-subunits are important modulators of the acute response to alcohol in human BK channels," Alcoholism, Clinical and Experimental Research, vol. 31, no. 5, pp. 737-744, 2007.

[256] K. Keleman, E. Vrontou, S. Krüttner, J. Y. Yu, A. KurtovicKozaric, and B. J. Dickson, "Dopamine neurons modulate pheromone responses in Drosophila courtship learning," Nature, vol. 489, no. 7414, pp. 145-149, 2012.

[257] E. C. Kong, K. Woo, H. Li et al., "A pair of dopamine neurons target the D1-like dopamine receptor DopR in the central complex to promote ethanol-stimulated locomotion in Drosophila," PLoS One, vol. 5, no. 4, article e9954, 2010.

[258] D. Ron and R. O. Messing, "Signaling pathways mediating alcohol effects," Current Topics in Behavioral Neurosciences, vol. 13, pp. 87-126, 2013.

[259] N. D. Volkow, G. J. Wang, F. Telang et al., "Profound decreases in dopamine release in striatum in detoxified alcoholics: possible orbitofrontal involvement," Journal of Neuroscience, vol. 27, no. 46, pp. 12700-12706, 2007.

[260] S. Waddell, "Reinforcement signalling in Drosophila; dopamine does it all after all," Current Opinion in Neurobiology, vol. 23, no. 3, pp. 324-329, 2013.

[261] R. J. Bainton, L. T. Tsai, C. M. Singh, M. S. Moore, W. S. Neckameyer, and U. Heberlein, "Dopamine modulates acute responses to cocaine, nicotine and ethanol in Drosophila," Current Biology, vol. 10, no. 4, pp. 187-194, 2000.

[262] O. Neznanova, K. Björk, R. Rimondini et al., "Acute ethanol challenge inhibits glycogen synthase kinase- $3 \beta$ in the rat prefrontal cortex," The International Journal of Neuropsychopharmacology, vol. 12, no. 2, pp. 275-280, 2009.

[263] K. E. Pleil, A. Lopez, N. McCall, A. M. Jijon, J. P. Bravo, and T. L. Kash, "Chronic stress alters neuropeptide Y signaling in the bed nucleus of the stria terminalis in DBA/2J but not C57BL/6J mice," Neuropharmacology, vol. 62, no. 4, pp. 1777-1786, 2012.

[264] K. E. Pleil, J. A. Rinker, E. G. Lowery-Gionta et al., "NPY signaling inhibits extended amygdala CRF neurons to suppress binge alcohol drinking," Nature Neuroscience, vol. 18, no. 4, pp. 545-552, 2015.

[265] N. W. Gilpin and M. Roberto, "Neuropeptide modulation of central amygdala neuroplasticity is a key mediator of alcohol dependence," Neuroscience and Biobehavioral Reviews, vol. 36, no. 2, pp. 873-888, 2012.
[266] A. M. Barkley-Levenson, A. E. Ryabinin, and J. C. Crabbe, "Neuropeptide Y response to alcohol is altered in nucleus accumbens of mice selectively bred for drinking to intoxication," Behavioural Brain Research, vol. 302, pp. 160-170, 2016.

[267] G. Shohat-Ophir, K. R. Kaun, R. Azanchi, H. Mohammed, and U. Heberlein, "Sexual deprivation increases ethanol intake in Drosophila," Science, vol. 335, no. 6074, pp. 1351$1355,2012$.

[268] T. Wen, C. A. Parrish, D. Xu, Q. Wu, and P. Shen, "Drosophila neuropeptide $\mathrm{F}$ and its receptor, NPFR1, define a signaling pathway that acutely modulates alcohol sensitivity," Proceedings of the National Academy of Sciences of the United States of America, vol. 102, no. 6, pp. 2141-6, 2005.

[269] H. Scholz, M. Franz, and U. Heberlein, "The hangover gene defines a stress pathway required for ethanol tolerance development," Nature, vol. 436, no. 7052, pp. 845-847, 2005.

[270] I. Schwenkert, R. Eltrop, N. Funk, J. R. Steinert, C. M. Schuster, and H. Scholz, "The hangover gene negatively regulates bouton addition at the Drosophila neuromuscular junction," Mechanisms of Development, vol. 125, no. 8, pp. 700-711, 2008.

[271] X. Ma, Q. Wang, G. Qin et al., "Predictive value of liver enzymes and alcohol consumption for risk of type 2 diabetes," Zhonghua Gan Zang Bing Za Zhi, vol. 23, no. 1, pp. 55-58, 2015.

[272] B. P. Riley, G. Kalsi, P. H. Kuo et al., "Alcohol dependence is associated with the ZNF699 gene, a human locus related to Drosophila hangover, in the Irish affected sib pair study of alcohol dependence (IASPSAD) sample," Molecular Psychiatry, vol. 11, no. 11, pp. 1025-1031, 2006.

[273] Z. W. Chen and R. W. Olsen, "GABA receptor associated proteins: a key factor regulating $\mathrm{GABA}_{\mathrm{A}}$ receptor function," Journal of Neurochemistry, vol. 100, no. 2, pp. 279-294, 2007.

[274] J. Zhou, J. Ye, X. Zhao, and A. Li, "JWA is required for arsenic trioxide induced apoptosis in HeLa and MCF-7 cells via reactive oxygen species and mitochondria linked signal pathway," Toxicology and Applied Pharmacology, vol. 230, no. 1, pp. 33-40, 2008.

[275] C. Li, X. Zhao, X. Cao, D. Chu, J. Chen, and J. Zhou, "The Drosophila homolog of jwa is required for ethanol tolerance," Alcohol and Alcoholism, vol. 43, no. 5, pp. 529-536, 2008.

[276] M. J. Ikemoto, K. Inoue, S. Akiduki et al., "Identification of addicsin/GTRAP3-18 as a chronic morphine-augmented gene in amygdala," Neuroreport, vol. 13, no. 16, pp. 20792084, 2002.

[277] S. A. Ojelade, T. Jia, A. R. Rodan et al., "Rsul regulates ethanol consumption in Drosophila and humans," Proceedings of the National Academy of Sciences of the United States of America, vol. 112, no. 30, pp. E4085-E4093, 2015.

[278] S. A. Ojelade, S. F. Acevedo, G. Kalahasti, A. R. Rodan, and A. Rothenfluh, "RhoGAP18B isoforms act on distinct rhofamily GTPases and regulate behavioral responses to alcohol via cofilin," PLoS One, vol. 10, no. 9, article e0137465, 2015.

[279] A. Rothenfluh, R. J. Threlkeld, R. J. Bainton, L. T. Tsai, A. W. Lasek, and U. Heberlein, "Distinct behavioral responses to ethanol are regulated by alternate RhoGAP18B isoforms," Cell, vol. 127, no. 1, pp. 199-211, 2006.

[280] P. Bhandari, K. S. Kendler, J. C. Bettinger, A. G. Davies, and M. Grotewiel, "An assay for evoked locomotor behavior in Drosophila reveals a role for integrins in ethanol sensitivity 
and rapid ethanol tolerance," Alcoholism, Clinical and Experimental Research, vol. 33, no. 10, pp. 1794-1805, 2009.

[281] S. F. Acevedo, R. L. Peru, R. L. Peru y Colón de Portugal, D. A. Gonzalez, A. R. Rodan, and A. Rothenfluh, "S6 kinase reflects and regulates ethanol-induced sedation," Journal of Neuroscience, vol. 35, no. 46, pp. 15396-15402, 2015.

[282] R. L. Peru y Colón de Portugal, S. F. Acevedo, A. R. Rodan, L. Y. Chang, B. A. Eaton, and A. Rothenfluh, "Adult neuronal Arf6 controls ethanol-induced behavior with arfaptin downstream of Racl and RhoGAP18B," Journal of Neuroscience, vol. 32, no. 49, pp. 17706-17713, 2012.

[283] D. A. Gonzalez, T. Jia, J. H. Pinzón et al., “The Arf6 activator Efa6/PSD3 confers regional specificity and modulates ethanol consumption in Drosophila and humans," Molecular Psychiatry, 2017.

[284] M. Grotewiel and J. C. Bettinger, "Drosophila and Caenorhabditis elegans as discovery platforms for genes involved in human alcohol use disorder," Alcoholism, Clinical and Experimental Research, vol. 39, no. 8, pp. 1292-1311, 2015.

[285] E. Haus and F. Halberg, "24-hour rhythm in susceptibility of C mice to a toxic dose of ethanol," Journal of Applied Physiology, vol. 14, pp. 878-880, 1959.

[286] M. D. Madeira, J. P. Andrade, A. R. Lieberman, N. Sousa, O. F. Almeida, and M. M. Paula-Barbosa, "Chronic alcohol consumption and withdrawal do not induce cell death in the suprachiasmatic nucleus, but lead to irreversible depression of peptide immunoreactivity and mRNA levels," Journal of Neuroscience, vol. 17, no. 4, pp. 1302-1319, 1997.

[287] V. Rajakrishnan, P. Subramanian, P. Viswanathan, and V. P. Menon, "Effect of chronic ethanol ingestion on biochemical circadian rhythms in Wistar rats," Alcohol, vol. 18, no. 2-3, pp. 147-152, 1999.

[288] R. Spanagel, A. M. Rosenwasser, G. Schumann, and D. K. Sarkar, "Alcohol consumption and the body's biological clock," Alcoholism, Clinical and Experimental Research, vol. 29, no. 8, pp. 1550-1557, 2005.

[289] E. Van Reen, T. L. Rupp, C. Acebo, R. Seifer, and M. A. Carskadon, "Biphasic effects of alcohol as a function of circadian phase," Sleep, vol. 36, no. 1, pp. 137-145, 2013.

[290] K. van der Linde and L. C. Lyons, "Circadian modulation of acute alcohol sensitivity but not acute tolerance in Drosophila," Chronobiology International, vol. 28, no. 5, pp. 397-406, 2011.

[291] S. Perreau-Lenz, T. Zghoul, F. R. de Fonseca, R. Spanagel, and A. Bilbao, "Circadian regulation of central ethanol sensitivity by the mPer2 gene," Addiction Biology, vol. 14, no. 3, pp. 253259, 2009.

[292] T. Danel, R. Jeanson, and Y. Touitou, “Temporal pattern in consumption of the first drink of the day in alcoholdependent persons," Chronobiology International, vol. 20, no. 6, pp. 1093-1102, 2003.

[293] T. Danel and Y. Touitou, "Chronobiology of alcohol: from chronokinetics to alcohol-related alterations of the circadian system," Chronobiology International, vol. 21, no. 6, pp. 923-935, 2004.

[294] J. B. Pohl, A. Ghezzi, L. K. Lew, R. B. Robles, L. Cormack, and N. S. Atkinson, "Circadian genes differentially affect tolerance to ethanol in Drosophila," Alcoholism, Clinical and Experimental Research, vol. 37, no. 11, pp. 1862-1871, 2013.

[295] J. Ewer, B. Frisch, M. J. Hamblen-Coyle, M. Rosbash, and J. C. Hall, "Expression of the period clock gene within different cell types in the brain of Drosophila adults and mosaic analysis of these cells' influence on circadian behavioral rhythms," Journal of Neuroscience, vol. 12, no. 9, pp. 33213349, 1992.

[296] J. L. Price, M. E. Dembinska, M. W. Young, and M. Rosbash, "Suppression of PERIOD protein abundance and circadian cycling by the Drosophila clock mutation timeless," The EMBO Journal, vol. 14, no. 16, pp. 4044-4049, 1995.

[297] T. Yoshii, Y. Heshiki, T. Ibuki-Ishibashi, A. Matsumoto, T. Tanimura, and K. Tomioka, "Temperature cycles drive Drosophila circadian oscillation in constant light that otherwise induces behavioural arrhythmicity," European Journal of Neuroscience, vol. 22, no. 5, pp. 1176-1184, 2005.

[298] A. K. De Nobrega, A. P. Mellers, and L. C. Lyons, "Aging and circadian dysfunction increase alcohol sensitivity and exacerbate mortality in Drosophila melanogaster," Experimental Gerontology, vol. 97, pp. 49-59, 2017.

[299] R. Spanagel, G. Pendyala, C. Abarca et al., “The clock gene Per2 influences the glutamatergic system and modulates alcohol consumption," Nature Medicine, vol. 11, no. 1, pp. 35-42, 2005.

[300] E. Comasco, N. Nordquist, C. Göktürk et al., "The clock gene PER2 and sleep problems: association with alcohol consumption among Swedish adolescents," Upsala Journal of Medical Sciences, vol. 115, no. 1, pp. 41-48, 2010.

[301] M. A. Agapito, J. C. Barreira, R. W. Logan, and D. K. Sarkar, "Evidence for possible period 2 gene mediation of the effects of alcohol exposure during the postnatal period on genes associated with maintaining metabolic signaling in the mouse hypothalamus," Alcoholism, Clinical and Experimental Research, vol. 37, no. 2, pp. 263-269, 2013.

[302] K. C. Summa, R. M. Voigt, C. B. Forsyth et al., "Disruption of the circadian clock in mice increases intestinal permeability and promotes alcohol-induced hepatic pathology and inflammation," PLoS One, vol. 8, no. 6, article e67102, 2013.

[303] K. C. Summa, P. Jiang, K. Fitzpatrick et al., "Chronic alcohol exposure and the circadian clock mutation exert tissuespecific effects on gene expression in mouse hippocampus, liver, and proximal colon," Alcoholism, Clinical and Experimental Research, vol. 39, no. 10, pp. 1917-1929, 2015.

[304] F. Bishehsari, A. Saadalla, K. Khazaie et al., "Light/dark shifting promotes alcohol-induced colon carcinogenesis: possible role of intestinal inflammatory milieu and microbiota," International Journal of Molecular Sciences, vol. 17, no. 12, 2016.

[305] J. A. Seggio, R. W. Logan, and A. M. Rosenwasser, "Chronic ethanol intake modulates photic and non-photic circadian phase responses in the Syrian hamster," Pharmacology, Biochemistry, and Behavior, vol. 87, no. 3, pp. 297-305, 2007.

[306] A. J. Brager, C. L. Ruby, R. A. Prosser, and J. D. Glass, “Acute ethanol disrupts photic and serotonergic circadian clock phase-resetting in the mouse," Alcoholism, Clinical and Experimental Research, vol. 35, no. 8, pp. 1467-1474, 2011.

[307] C. L. Ruby, A. J. Brager, M. A. DePaul, R. A. Prosser, and J. D. Glass, "Chronic ethanol attenuates circadian photic phase resetting and alters nocturnal activity patterns in the hamster," American Journal of Physiology - Regulatory, Integrative and Comparative Physiology, vol. 297, no. 3, pp. R729-R737, 2009.

[308] C. L. Ruby, R. A. Prosser, M. A. DePaul, R. J. Roberts, and J. D. Glass, "Acute ethanol impairs photic and nonphotic circadian phase resetting in the Syrian hamster," American 
Journal of Physiology - Regulatory, Integrative and Comparative Physiology, vol. 296, no. 2, pp. R411-R418, 2009.

[309] R. A. Prosser and J. D. Glass, “Assessing ethanol's actions in the suprachiasmatic circadian clock using in vivo and in vitro approaches," Alcohol, vol. 49, no. 4, pp.321-339, 2015.

[310] T. Partonen, "Clock genes in human alcohol abuse and comorbid conditions," Alcohol, vol. 49, no. 4, pp. 359-365, 2015.

[311] S. Perreau-Lenz and R. Spanagel, "Clock genes $\times$ stress $\times$ reward interactions in alcohol and substance use disorders," Alcohol, vol. 49, no. 4, pp. 351-357, 2015.

[312] M. C. Huang, C. W. Ho, C. H. Chen, S. C. Liu, C. C. Chen, and S. J. Leu, "Reduced expression of circadian clock genes in male alcoholic patients," Alcoholism, Clinical and Experimental Research, vol. 34, no. 11, pp. 1899-1904, 2010.

[313] H. J. Burgess, M. Rizvydeen, L. F. Fogg, and A. Keshavarzian, "A single dose of alcohol does not meaningfully alter circadian phase advances and phase delays to light in humans," American Journal of Physiology - Regulatory, Integrative and Comparative Physiology, vol. 310, no. 8, pp. R759-R765, 2016.

[314] R. Guo, S. M. Simasko, and H. T. Jansen, "Chronic alcohol consumption in rats leads to desynchrony in diurnal rhythms and molecular clocks," Alcoholism, Clinical and Experimental Research, vol. 40, no. 2, pp. 291-300, 2016.

[315] P. Zhou, R. A. Ross, C. M. Pywell, S. Liangpunsakul, and G. E. Duffield, "Disturbances in the murine hepatic circadian clock in alcohol-induced hepatic steatosis," Scientific Reports, vol. 4, p. 3725, 2014.

[316] G. Swanson, C. B. Forsyth, Y. Tang et al., "Role of intestinal circadian genes in alcohol-induced gut leakiness," Alcoholism, Clinical and Experimental Research, vol. 35, no. 7, pp. 1305-1314, 2011.

[317] A. N. Filiano, T. Millender-Swain, R. Johnson, M. E. Young, K. L. Gamble, and S. M. Bailey, "Chronic ethanol consumption disrupts the core molecular clock and diurnal rhythms of metabolic genes in the liver without affecting the suprachiasmatic nucleus," PLoS One, vol. 8, no. 8, article e71684, 2013.

[318] C. P. Chen, P. Kuhn, J. P. Advis, and D. K. Sarkar, “6," Journal of Neurochemistry, vol. 88, no. 6, pp. 1547-1554, 2004.

[319] J. A. Seggio, B. Possidente, and S. T. Ahmad, "Larval ethanol exposure alters adult circadian free-running locomotor activity rhythm in Drosophila melanogaster," Chronobiology International, vol. 29, no. 1, pp. 75-81, 2012.

[320] S. T. Ahmad, S. B. Steinmetz, H. M. Bussey, B. Possidente, and J. A. Seggio, "Larval ethanol exposure alters freerunning circadian rhythm and per Locus transcription in adult D. melanogaster period mutants," Behavioural Brain Research, vol. 241, pp. 50-55, 2013.

[321] R. Sandyk and J. D. Kanofsky, "Cocaine addiction: relationship to seasonal affective disorder," International Journal of Neuroscience, vol. 64, no. 1-4, pp. 195-201, 1992.

[322] S. L. Satel and F. H. Gawin, "Seasonal cocaine abuse," American Journal of Psychiatry, vol. 146, no. 4, pp. 534-535, 1989.

[323] Y. Iijima, M. Shinoda, H. Kuribara, T. Asami, and Y. Uchihashi, "Evaluation of acute and sub-acute effects of cocaine by means of circadian variation in wheel-running and drinking in mice," Nihon Shinkei Seishin Yakurigaku Zasshi, vol. 15, no. 4, pp. 315-321, 1995.

[324] C. Abarca, U. Albrecht, and R. Spanagel, "Cocaine sensitization and reward are under the influence of circadian genes and rhythm," Proceedings of the National Academy of Sciences of the United States of America, vol. 99, no. 13, pp. 9026-9030, 2002.

[325] M. Akhisaroglu, R. Ahmed, M. Kurtuncu, H. Manev, and T. Uz, "Diurnal rhythms in cocaine sensitization and in Period1 levels are common across rodent species," Pharmacology, Biochemistry, and Behavior, vol. 79, no. 1, pp. 37-42, 2004.

[326] T. Uz, M. Akhisaroglu, R. Ahmed, and H. Manev, "The pineal gland is critical for circadian Period1 expression in the striatum and for circadian cocaine sensitization in mice," Neuropsychopharmacology, vol. 28, no. 12, pp. 2117-2123, 2003.

[327] T. J. Baird and D. Gauvin, "Characterization of cocaine selfadministration and pharmacokinetics as a function of time of day in the rat," Pharmacology, Biochemistry, and Behavior, vol. 65, no. 2, pp. 289-299, 2000.

[328] J. D. Glass, A. J. Brager, A. C. Stowie, and R. A. Prosser, "Cocaine modulates pathways for photic and nonphotic entrainment of the mammalian SCN circadian clock," American Journal of Physiology - Regulatory, Integrative and Comparative Physiology, vol. 302, no. 6, pp. R740-R750, 2012.

[329] R. A. Prosser, A. Stowie, M. Amicarelli, A. G. Nackenoff, R. D. Blakely, and J. D. Glass, "Cocaine modulates mammalian circadian clock timing by decreasing serotonin transport in the SCN," Neuroscience, vol. 275, pp. 184-193, 2014.

[330] V. Yuferov, T. Kroslak, K. S. Laforge, Y. Zhou, A. Ho, and M. J. Kreek, "Differential gene expression in the rat caudate putamen after "binge" cocaine administration: advantage of triplicate microarray analysis," Synapse, vol. 48, no. 4, pp. 157-169, 2003.

[331] R. George, K. Lease, J. Burnette, and J. Hirsh, "A "bottomcounting" video system for measuring cocaine-induced behaviors in Drosophila," Methods in Enzymology, vol. 393, pp. 841-851, 2005.

[332] C. McClung and J. Hirsh, "Stereotypic behavioral responses to free-base cocaine and the development of behavioral sensitization in Drosophila," Current Biology, vol. 8, no. 2, pp. 109-112, 1998.

[333] L. T. Tsai, R. J. Bainton, J. Blau, and U. Heberlein, "Lmo mutants reveal a novel role for circadian pacemaker neurons in cocaine-induced behaviors," PLoS Biology, vol. 2, no. 12, article e408, 2004.

[334] R. Andretic, S. Chaney, and J. Hirsh, "Requirement of circadian genes for cocaine sensitization in Drosophila," Science, vol. 285, no. 5430, pp. 1066-1068, 1999.

[335] E. Shumay, J. S. Fowler, G. J. Wang et al., "Repeat variation in the human PER2 gene as a new genetic marker associated with cocaine addiction and brain dopamine D2 receptor availability," Translational Psychiatry, vol. 2, article e86, 2012.

[336] C. A. McClung, K. Sidiropoulou, M. Vitaterna et al., "Regulation of dopaminergic transmission and cocaine reward by the Clock gene," Proceedings of the National Academy of Sciences of the United States of America, vol. 102, no. 26, pp. 93779381, 2005.

[337] A. R. Ozburn, E. B. Larson, D. W. Self, and C. A. McClung, "Cocaine self-administration behaviors in Clock $\Delta 19$ mice," Psychopharmacology, vol. 223, no. 2, pp. 169-177, 2012.

[338] U. Heberlein, L. T. Tsai, D. Kapfhamer, and A. W. Lasek, "Drosophila, a genetic model system to study cocaine- 
related behaviors: a review with focus on LIM-only proteins," Neuropharmacology, vol. 56, Supplement 1, pp. 97-106, 2009.

[339] R. M. Harris-Warrick and E. A. Kravitz, "Cellular mechanisms for modulation of posture by octopamine and serotonin in the lobster," Journal of Neuroscience, vol. 4, no. 8, pp. 1976-1993, 1984.

[340] E. A. Kravitz, S. Glusman, R. M. Harris-Warrick, M. S. Livingstone, T. Schwarz, and M. F. Goy, "Amines and a peptide as neurohormones in lobsters: actions on neuromuscular preparations and preliminary behavioural studies," Journal of Experimental Biology, vol. 89, pp. 159-175, 1980.

[341] B. D. Sloley and A. V. Juorio, "Monoamine neurotransmitters in invertebrates and vertebrates: an examination of the diverse enzymatic pathways utilized to synthesize and inactivate biogenic amines," International Review of Neurobiology, vol. 38, pp. 253-303, 1995.

[342] J. R. Cazalets, P. Grillner, I. Menard, J. Cremieux, and F. Clarac, "Two types of motor rhythm induced by NMDA and amines in an in vitro spinal cord preparation of neonatal rat," Neuroscience Letters, vol. 111, no. 1-2, pp. 116-121, 1990.

[343] M. Matsumoto and O. Hikosaka, "Two types of dopamine neuron distinctly convey positive and negative motivational signals," Nature, vol. 459, no. 7248, pp. 837-841, 2009.

[344] H. M. Nasser, D. J. Calu, G. Schoenbaum, and M. J. Sharpe, "The dopamine prediction error: contributions to associative models of reward learning," Frontiers in Psychology, vol. 8, p. 244, 2017.

[345] C. J. Perry and A. B. Barron, "Neural mechanisms of reward in insects," Annual Review of Entomology, vol. 58, pp. 543$562,2013$.

[346] G. F. Koob and N. D. Volkow, "Neurobiology of addiction: a neurocircuitry analysis," Lancet Psychiatry, vol. 3, no. 8, pp. 760-773, 2016.

[347] R. Andretic and J. Hirsh, "Circadian modulation of dopamine receptor responsiveness in Drosophila melanogaster," Proceedings of the National Academy of Sciences of the United States of America, vol. 97, no. 4, pp. 1873-1878, 2000.

[348] C. A. McClung, "Circadian rhythms, the mesolimbic dopaminergic circuit, and drug addiction," Scientific World Journal, vol. 7, pp. 194-202, 2007.

[349] M. J. Lee, K. D. Burau, and N. Dafny, "Behavioral daily rhythmic activity pattern of adolescent female rat is modulated by acute and chronic cocaine," Journal of Neural Transmission, vol. 120, no. 5, pp. 733-744, 2013.

[350] M. Weber, T. Lauterburg, I. Tobler, and J. M. Burgunder, "Circadian patterns of neurotransmitter related gene expression in motor regions of the rat brain," Neuroscience Letters, vol. 358, no. 1, pp. 17-20, 2004.

[351] K. R. Shieh, Y. S. Chu, and J. T. Pan, "Circadian change of dopaminergic neuron activity: effects of constant light and melatonin," Neuroreport, vol. 8, no. 9-10, pp. 2283-2287, 1997.

[352] R. Schade, K. Vick, T. Ott et al., "Circadian rhythms of dopamine and cholecystokinin in nucleus accumbens and striatum of rats-influence on dopaminergic stimulation," Chronobiology International, vol. 12, no. 2, pp. 87-99, 1995.

[353] P. K. Parekh, A. R. Ozburn, and C. A. McClung, "Circadian clock genes: effects on dopamine, reward and addiction," Alcohol, vol. 49, no. 4, pp. 341-349, 2015.
[354] I. C. Webb, "Circadian rhythms and substance abuse: chronobiological considerations for the treatment of addiction," Current Psychiatry Reports, vol. 19, no. 2, p. 12, 2017.

[355] R. W. Logan, W. P. Williams, and C. A. McClung, "Circadian rhythms and addiction: mechanistic insights and future directions," Behavioral Neuroscience, vol. 128, no. 3, pp. 387-412, 2014.

[356] M. Kurtuncu, A. D. Arslan, M. Akhisaroglu, H. Manev, and T. Uz, "Involvement of the pineal gland in diurnal cocaine reward in mice," European Journal of Pharmacology, vol. 489, no. 3, pp. 203-205, 2004.

[357] T. T. Takahashi, V. Vengeliene, and R. Spanagel, "Melatonin reduces motivation for cocaine self-administration and prevents relapse-like behavior in rats," Psychopharmacology, vol. 234, no. 11, pp. 1741-1748, 2017.

[358] B. Halbout, S. Perreau-Lenz, C. I. Dixon, D. N. Stephens, and R. Spanagel, "Per1Brdm1 mice self-administer cocaine and reinstate cocaine-seeking behaviour following extinction," Behavioural Pharmacology, vol. 22, no. 1, pp. 7680, 2011.

[359] Y. Liu, Y. Wang, Z. Jiang, C. Wan, W. Zhou, and Z. Wang, "The extracellular signal-regulated kinase signaling pathway is involved in the modulation of morphine-induced reward by mPer1," Neuroscience, vol. 146, no. 1, pp. 265-271, 2007.

[360] Y. Liu, Y. Wang, C. Wan et al., "The role of mPer1 in morphine dependence in mice," Neuroscience, vol. 130, no. 2, pp. 383-388, 2005.

[361] X. Wang, Y. Wang, H. Xin et al., “Altered expression of circadian clock gene, mPer1, in mouse brain and kidney under morphine dependence and withdrawal," Journal of Circadian Rhythms, vol. 4, p. 9, 2006.

[362] T. Nikaido, M. Akiyama, T. Moriya, and S. Shibata, "Sensitized increase of period gene expression in the mouse caudate/putamen caused by repeated injection of methamphetamine," Molecular Pharmacology, vol. 59, no. 4, pp. 894-900, 2001.

[363] N. Fuenzalida-Uribe, R. C. Meza, H. A. Hoffmann, R. Varas, and J. M. Campusano, "nAChR-induced octopamine release mediates the effect of nicotine on a startle response in Drosophila melanogaster," Journal of Neurochemistry, vol. 125, no. 2, pp. 281-290, 2013.

[364] R. Andretic, B. van Swinderen, and R. J. Greenspan, "Dopaminergic modulation of arousal in Drosophila," Current Biology, vol. 15, no. 13, pp. 1165-1175, 2005.

[365] E. Tekieh, M. Kazemi, L. Dehghani et al., "Effects of oral morphine on the larvae, pupae and imago development in Drosophila melanogaster," Cell Journal, vol. 13, no. 3, pp. 149-154, 2011.

[366] N. A. Velazquez-Ulloa, "A Drosophila model for developmental nicotine exposure," PLoS One, vol. 12, no. 5, article e0177710, 2017.

[367] E. S. Barratt and P. M. Adams, "Chronic marijuana usage and sleep-wakefulness cycles in cats," Biological Psychiatry, vol. 6, no. 3, pp. 207-214, 1973.

[368] A. E. Sanford, E. Castillo, and R. L. Gannon, "Cannabinoids and hamster circadian activity rhythms," Brain Research, vol. 1222, pp. 141-148, 2008.

[369] L. N. Whitehurst, K. Fogler, K. Hall, M. Hartmann, and J. Dyche, "The effects of chronic marijuana use on circadian entrainment," Chronobiology International, vol. 32, no. 4, pp. 561-567, 2015. 
[370] C. Acuna-Goycolea, K. Obrietan, and A. N. van den Pol, "Cannabinoids excite circadian clock neurons," Journal of Neuroscience, vol. 30, no. 30, pp. 10061-10066, 2010.

[371] J. R. Tinklenberg, W. T. Roth, and B. S. Kopell, "Marijuana and ethanol: differential effects on time perception, heart rate, and subjective response," Psychopharmacology, vol. 49, no. 3, pp. 275-279, 1976.

[372] D. S. Hasin, T. D. Saha, B. T. Kerridge et al., "Prevalence of marijuana use disorders in the United States between 2001-2002 and 2012-2013," JAMA Psychiatry, vol. 72, no. 12, pp. 1235-1242, 2015.

[373] H. Khaliullina, M. Bilgin, J. L. Sampaio, A. Shevchenko, and S. Eaton, "Endocannabinoids are conserved inhibitors of the Hedgehog pathway," Proceedings of the National Academy of Sciences of the United States of America, vol. 112, no. 11, pp. 3415-3420, 2015.

[374] M. Jimenez-Del-Rio, A. Daza-Restrepo, and C. Velez-Pardo, "The cannabinoid CP55,940 prolongs survival and improves locomotor activity in Drosophila melanogaster against paraquat: implications in Parkinson's disease," Neuroscience Research, vol. 61, no. 4, pp. 404-411, 2008.

[375] M. J. Lee, M. S. Park, S. Hwang et al., "Dietary hempseed meal intake increases body growth and shortens the larval stage via the upregulation of cell growth and sterol levels in Drosophila melanogaster," Molecules and Cells, vol. 30, no. 1, pp. 29-36, 2010.

[376] R. L. Hartman, T. L. Brown, G. Milavetz et al., "Controlled vaporized cannabis, with and without alcohol: subjective effects and oral fluid-blood cannabinoid relationships," Drug Testing and Analysis, vol. 8, no. 7, pp. 690-701, 2016.

[377] R. L. Hartman, T. L. Brown, G. Milavetz et al., "Cannabis effects on driving lateral control with and without alcohol," Drug and Alcohol Dependence, vol. 154, pp. 25-37, 2015.

[378] J. Hayaki, B. J. Anderson, and M. D. Stein, "Dual cannabis and alcohol use disorders in young adults: problems magnified," Substance Abuse, vol. 37, no. 4, pp. 579-583, 2016.

[379] J. F. Duffy, K. M. Zitting, and E. D. Chinoy, "Aging and circadian rhythms," Sleep Medicine Clinics, vol. 10, no. 4, pp. 423-434, 2015.

[380] J. Mattis and A. Sehgal, "Circadian rhythms, sleep, and disorders of aging," Trends in Endocrinology and Metabolism, vol. 27, no. 4, pp. 192-203, 2016.

[381] S. Benloucif, M. I. Masana, and M. L. Dubocovich, "Lightinduced phase shifts of circadian activity rhythms and immediate early gene expression in the suprachiasmatic nucleus are attenuated in old $\mathrm{C} 3 \mathrm{H} / \mathrm{HeN}$ mice," Brain Research, vol. 747, no. 1, pp. 34-42, 1997.

[382] C. Y. Chen, R. W. Logan, T. Ma et al., "Effects of aging on circadian patterns of gene expression in the human prefrontal cortex," Proceedings of the National Academy of Sciences of the United States of America, vol. 113, no. 1, pp. 206-211, 2016.

[383] A. Novier, L. C. Ornelas, J. L. Diaz-Granados, and D. B. Matthews, "Differences in behavioral responding in adult and aged rats following chronic ethanol exposure," Alcoholism, Clinical and Experimental Research, vol. 40, no. 7, pp. 1462-1472, 2016.

[384] A. Novier, C. E. Van Skike, J. L. Diaz-Granados, G. Mittleman, and D. B. Matthews, "Acute alcohol produces ataxia and cognitive impairments in aged animals: a comparison between young adult and aged rats," Alcoholism, Clinical and Experimental Research, vol. 37, no. 8, pp. 1317-1324, 2013.

[385] International Human Genome Sequencing Consortium, "Finishing the euchromatic sequence of the human genome," Nature, vol. 431, no. 7011, pp. 931-945, 2004.

[386] B. Ugur, K. Chen, and H. J. Bellen, "Drosophila tools and assays for the study of human diseases," Disease Models \& Mechanisms, vol. 9, no. 3, pp. 235-244, 2016.

[387] N. Perrimon, N. M. Bonini, and P. Dhillon, "Fruit flies on the front line: the translational impact of Drosophila," Disease Models \& Mechanisms, vol. 9, no. 3, pp. 229-231, 2016.

[388] N. Perrimon, C. Pitsouli, and B. Z. Shilo, "Signaling mechanisms controlling cell fate and embryonic patterning," Cold Spring Harbor Perspectives in Biology, vol. 4, no. 8, article a005975, 2012.

[389] S. Chien, L. T. Reiter, E. Bier, and M. Gribskov, "Homophila: human disease gene cognates in Drosophila," Nucleic Acids Research, vol. 30, no. 1, pp. 149-151, 2002.

[390] S. Yamamoto, M. Jaiswal, W. L. Charng et al., "A Drosophila genetic resource of mutants to study mechanisms underlying human genetic diseases," Cell, vol. 159, no. 1, pp. 200-214, 2014.

[391] K. H. Berger, E. C. Kong, J. Dubnau, T. Tully, M. S. Moore, and U. Heberlein, "Ethanol sensitivity and tolerance in long-term memory mutants of Drosophila melanogaster," Alcoholism, Clinical and Experimental Research, vol. 32, no. 5, pp. 895-908, 2008.

[392] G. Dietzl, D. Chen, F. Schnorrer et al., “A genome-wide transgenic RNAi library for conditional gene inactivation in Drosophila," Nature, vol. 448, no. 7150, pp. 151-156, 2007.

[393] T. A. Fulga, E. M. McNeill, R. Binari et al., "A transgenic resource for conditional competitive inhibition of conserved Drosophila microRNAs," Nature Communications, vol. 6, p. 7279, 2015.

[394] A. R. Bassett and J. L. Liu, "CRISPR/Cas9 and genome editing in Drosophila," Journal of Genetics and Genomics, vol. 41, no. 1, pp. 7-19, 2014.

[395] J. Xu, X. Ren, J. Sun et al., "A toolkit of CRISPR-based genome editing systems in Drosophila," Journal of Genetics and Genomics, vol. 42, no. 4, pp. 141-149, 2015.

[396] R. Ghaemi and P. R. Selvaganapathy, "Microfluidic devices for automation of assays on Drosophila melanogaster for applications in drug discovery and biological studies," Current Pharmaceutical Biotechnology, vol. 17, no. 9, pp. 822836, 2016.

[397] A. K. Yadav, S. Srikrishna, and S. C. Gupta, "Cancer drug development using Drosophila as an in vivo tool: from bedside to bench and back," Trends in Pharmacological Sciences, vol. 37, no. 9, pp. 789-806, 2016.

[398] N. Cadieu, J. Cadieu, L. El Ghadraoui, A. Grimal, and Y. Lamboeuf, "Conditioning to ethanol in the fruit fly-a study using an inhibitor of ADH," Journal of Insect Physiology, vol. 45, no. 6, pp. 579-586, 1999.

[399] M. B. Acevedo, M. E. Nizhnikov, N. E. Spear, J. C. Molina, and R. M. Pautassi, "Ethanol-induced locomotor activity in adolescent rats and the relationship with ethanol-induced conditioned place preference and conditioned taste aversion," Developmental Psychobiology, vol. 55, no. 4, pp. 429442, 2013

[400] N. A. Holtz, A. K. Radke, N. E. Zlebnik, A. C. Harris, and M. E. Carroll, "Intracranial self-stimulation reward 
thresholds during morphine withdrawal in rats bred for high (HiS) and low (LoS) saccharin intake," Brain Research, vol. 1602, pp. 119-126, 2015.

[401] F. D. Zeeb, G. A. Higgins, and P. J. Fletcher, "The serotonin $2 \mathrm{C}$ receptor agonist lorcaserin attenuates intracranial selfstimulation and blocks the reward-enhancing effects of nicotine," ACS Chemical Neuroscience, vol. 6, no. 7, pp. 1231-1240, 2015.

[402] B. T. Lett and V. L. Grant, "Conditioned taste preference produced by pairing a taste with a low dose of morphine or sufentanil," Psychopharmacology, vol. 98, no. 2, pp. 236239, 1989.

[403] Z. I. Su, J. Wenzel, A. Ettenberg, and O. Ben-Shahar, "Prior extended daily access to cocaine elevates the reward threshold in a conditioned place preference test," Addiction Biology, vol. 19, no. 5, pp. 826-837, 2014.

[404] H. B. Madsen and S. H. Ahmed, "Drug versus sweet reward: greater attraction to and preference for sweet versus drug cues," Addiction Biology, vol. 20, no. 3, pp. 433-444, 2015.

[405] C. M. Davis, I. de Brugada, and A. L. Riley, "The role of injection cues in the production of the morphine preexposure effect in taste aversion learning," Learning \& Behavior, vol. 38, no. 2, pp. 103-110, 2010.

[406] H. E. King and A. L. Riley, "A history of morphine-induced taste aversion learning fails to affect morphine-induced place preference conditioning in rats," Learning \& Behavior, vol. 41, no. 4, pp. 433-442, 2013.

[407] D. J. Fachin-Scheit, A. Frozino Ribeiro, G. Pigatto, F. Oliveira Goeldner, and R. Boerngen de Lacerda, "Development of a mouse model of ethanol addiction: naltrexone efficacy in reducing consumption but not craving," Journal of Neural Transmission, vol. 113, no. 9, pp. 1305-1321, 2006.

[408] B. R. Lee, Y. Y. Ma, Y. H. Huang et al., "Maturation of silent synapses in amygdala-accumbens projection contributes to incubation of cocaine craving," Nature Neuroscience, vol. 16, no. 11, pp. 1644-1651, 2013.

[409] A. Shahbabaie, M. Golesorkhi, B. Zamanian et al., "State dependent effect of transcranial direct current stimulation (tDCS) on methamphetamine craving," The International Journal of Neuropsychopharmacology, vol. 17, no. 10, pp. 1591-1598, 2014.

[410] B. Wang, B. Zhang, X. Ge, F. Luo, and J. Han, "Inhibition by peripheral electric stimulation of the reinstatement of morphine-induced place preference in rats and drugcraving in heroin addicts," Beijing Da Xue Xue Bao Yi Xue Ban, vol. 35, no. 3, pp. 241-247, 2003.

[411] C. Quoilin, V. Didone, E. Tirelli, and E. Quertemont, "Chronic tolerance to ethanol-induced sedation: implication for age-related differences in locomotor sensitization," Alcohol, vol. 47, no. 4, pp. 317-322, 2013.

[412] P. Maccioni, D. Vargiolu, A. W. Thomas et al., "Inhibition of alcohol self-administration by positive allosteric modulators of the $\mathrm{GABA}_{\mathrm{B}}$ receptor in rats: lack of tolerance and potentiation of baclofen," Psychopharmacology, vol. 232, no. 10, pp. 1831-1841, 2015.

[413] C. Arias, D. A. Revillo, and N. E. Spear, "Chronic tolerance to the locomotor stimulating effect of ethanol in preweanling rats as a function of social stress," Alcohol, vol. 46, no. 3, pp. 245-252, 2012.

[414] S. Talarek, J. Orzelska, J. Listos, and S. Fidecka, "Effects of sildenafil treatment on the development of tolerance to diazepam-induced motor impairment and sedation in mice," Pharmacological Reports, vol. 62, no. 4, pp. 627-634, 2010.

[415] H. Li, S. Chaney, I. J. Roberts, M. Forte, and J. Hirsh, "Ectopic G-protein expression in dopamine and serotonin neurons blocks cocaine sensitization in Drosophila melanogaster," Current Biology, vol. 10, no. 4, pp. 211-4, 2000.

[416] C. McClung and J. Hirsh, "The trace amine tyramine is essential for sensitization to cocaine in Drosophila," Current Biology, vol. 9, no. 16, pp. 853-860, 1999.

[417] E. S. Calipari, M. J. Ferris, C. A. Siciliano, B. A. Zimmer, and S. R. Jones, "Intermittent cocaine self-administration produces sensitization of stimulant effects at the dopamine transporter," Journal of Pharmacology and Experimental Therapeutics, vol. 349, no. 2, pp. 192-198, 2014.

[418] N. R. Gubner and T. J. Phillips, "Effects of nicotine on ethanol-induced locomotor sensitization: a model of neuroadaptation," Behavioural Brain Research, vol. 288, pp. 26-32, 2015.

[419] E. Valjent, J. Bertran-Gonzalez, B. Aubier, P. Greengard, D. Hervé, and J. A. Girault, "Mechanisms of locomotor sensitization to drugs of abuse in a two-injection protocol," Neuropsychopharmacology, vol. 35, no. 2, pp. 401-415, 2010.

[420] J. Zhu, N. M. Midde, A. M. Gomez, W. L. Sun, and S. B. Harrod, "Intra-ventral tegmental area HIV-1 Tat1-86 attenuates nicotine-mediated locomotor sensitization and alters mesocorticolimbic ERK and CREB signaling in rats," Frontiers in Microbiology, vol. 6, p. 540, 2015.

[421] A. Ghezzi, H. R. Krishnan, and N. S. Atkinson, "Susceptibility to ethanol withdrawal seizures is produced by BK channel gene expression," Addiction Biology, vol. 19, no. 3, pp. 332337, 2014.

[422] X. Li, A. Ghezzi, J. B. Pohl, A. Y. Bohm, and N. S. Atkinson, "A DNA element regulates drug tolerance and withdrawal in Drosophila," PLoS One, vol. 8, no. 9, article e75549, 2013.

[423] S. Perreau-Lenz, C. Sanchis-Segura, F. Leonardi-Essmann, M. Schneider, and R. Spanagel, "Development of morphineinduced tolerance and withdrawal: involvement of the clock gene mPer2," European Neuropsychopharmacology, vol. 20, no. 7, pp. 509-517, 2010.

[424] S. M. Bhisikar, D. M. Kokare, K. T. Nakhate, C. T. Chopde, and N. K. Subhedar, "Tolerance to ethanol sedation and withdrawal hyper-excitability is mediated via neuropeptide Y Y1 and Y5 receptors," Life Sciences, vol. 85, no. 21-22, pp. 765-772, 2009.

[425] M. Naassila, O. Pierrefiche, C. Ledent, and M. Daoust, "Decreased alcohol self-administration and increased alcohol sensitivity and withdrawal in CB1 receptor knockout mice," Neuropharmacology, vol. 46, no. 2, pp. 243-253, 2004.

[426] C. G. Jang, T. Whitfield, G. Schulteis, G. F. Koob, and S. Wee, "A dysphoric-like state during early withdrawal from extended access to methamphetamine self-administration in rats," Psychopharmacology, vol. 225, no. 3, pp. 753763, 2013.

[427] J. F. McGinty, A. Zelek-Molik, and W. L. Sun, "Cocaine self-administration causes signaling deficits in corticostriatal circuitry that are reversed by BDNF in early withdrawal," Brain Research, vol. 1628, Part A, pp. 82-87, 2015.

[428] B. G. Robinson, S. Khurana, A. Kuperman, and N. S. Atkinson, "Neural adaptation leads to cognitive ethanol dependence," Current Biology, vol. 22, no. 24, pp. 2338 2341, 2012. 
[429] Y. Chen, R. Song, R. F. Yang, N. Wu, and J. Li, “A novel dopamine D3 receptor antagonist YQA14 inhibits methamphetamine self-administration and relapse to drug-seeking behaviour in rats," European Journal of Pharmacology, vol. 743, pp. 126-132, 2014.

[430] M. L. Logrip, L. F. Vendruscolo, J. E. Schlosburg, G. F. Koob, and E. P. Zorrilla, "Phosphodiesterase 10A regulates alcohol and saccharin self-administration in rats," Neuropsychopharmacology, vol. 39, no. 7, pp. 1722-1731, 2014.

[431] A. Cooper, N. Barnea-Ygael, D. Levy, Y. Shaham, and A. Zangen, "A conflict rat model of cue-induced relapse to cocaine seeking," Psychopharmacology, vol. 194, no. 1, pp. 117-125, 2007.

[432] N. J. Marchant, T. N. Khuc, C. L. Pickens, A. Bonci, and Y. Shaham, "Context-induced relapse to alcohol seeking after punishment in a rat model," Biological Psychiatry, vol. 73, no. 3, pp. 256-262, 2013.

[433] Z. J. Brown, J. N. Nobrega, and S. Erb, "Central injections of noradrenaline induce reinstatement of cocaine seeking and increase c-fos mRNA expression in the extended amygdala," Behavioural Brain Research, vol. 217, no. 2, pp. 472-476, 2011.

[434] A. R. Ozburn, R. A. Harris, and Y. A. Blednov, "Chronic voluntary alcohol consumption results in tolerance to sedative/ hypnotic and hypothermic effects of alcohol in hybrid mice," Pharmacology, Biochemistry, and Behavior, vol. 104, pp. 3339, 2013.

[435] B. Garmabi, N. Vousooghi, M. Vosough, A. Yoonessi, A. Bakhtazad, and M. R. Zarrindast, "Effect of circadian rhythm disturbance on morphine preference and addiction in male rats: involvement of period genes and dopamine D1 receptor," Neuroscience, vol. 322, pp. 104-114, 2016.

[436] P. Wongchitrat, S. Mukda, P. Phansuwan-Pujito, and P. Govitrapong, "Effect of amphetamine on the clock gene expression in rat striatum," Neuroscience Letters, vol. 542, pp. 126-130, 2013.

[437] S. X. Li, L. J. Liu, W. G. Jiang, and L. Lu, "Morphine withdrawal produces circadian rhythm alterations of clock genes in mesolimbic brain areas and peripheral blood mononuclear cells in rats," Journal of Neurochemistry, vol. 109, no. 6, pp. 1668-1679, 2009.

[438] S. Masubuchi, S. Honma, H. Abe, W. Nakamura, and K. Honma, "Circadian activity rhythm in methamphetamine-treated Clock mutant mice," European Journal of Neuroscience, vol. 14, no. 7, pp. 1177-1180, 2001.

[439] C. D. Bryant, M. E. Graham, M. G. Distler et al., "A role for casein kinase 1 epsilon in the locomotor stimulant response to methamphetamine," Psychopharmacology, vol. 203, no. 4, pp. 703-711, 2009.

[440] C. D. Bryant, C. C. Parker, L. Zhou et al., "Csnk1e is a genetic regulator of sensitivity to psychostimulants and opioids," Neuropsychopharmacology, vol. 37, no. 4, pp. 1026-1035, 2012.

[441] D. Li, S. Herrera, N. Bubula et al., "Casein kinase 1 enables nucleus accumbens amphetamine-induced locomotion by regulating AMPA receptor phosphorylation," Journal of Neurochemistry, vol. 118, no. 2, pp. 237-247, 2011.
[442] Y. Zhang, P. Svenningsson, R. Picetti et al., "Cocaine selfadministration in mice is inversely related to phosphorylation at Thr34 (protein kinase A site) and Ser130 (kinase CK1 site) of DARPP-32," Journal of Neuroscience, vol. 26, no. 10, pp. 2645-2651, 2006.

[443] A. W. Lasek, D. Kapfhamer, V. Kharazia, J. Gesch, F. Giorgetti, and U. Heberlein, "Lmo4 in the nucleus accumbens regulates cocaine sensitivity," Genes, Brain and Behavior, vol. 9, no. 7, pp. 817-824, 2010. 

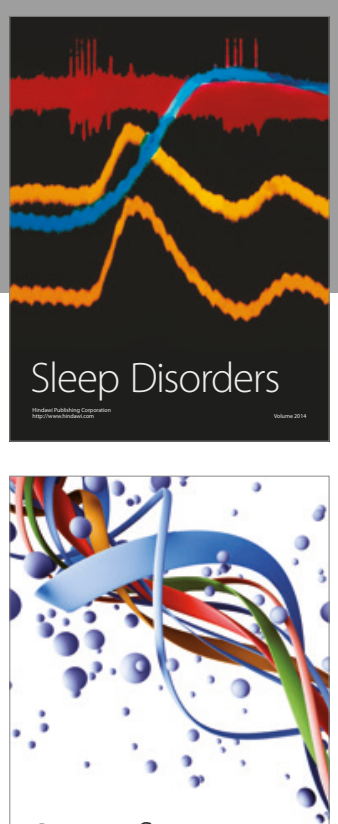

Scientifica
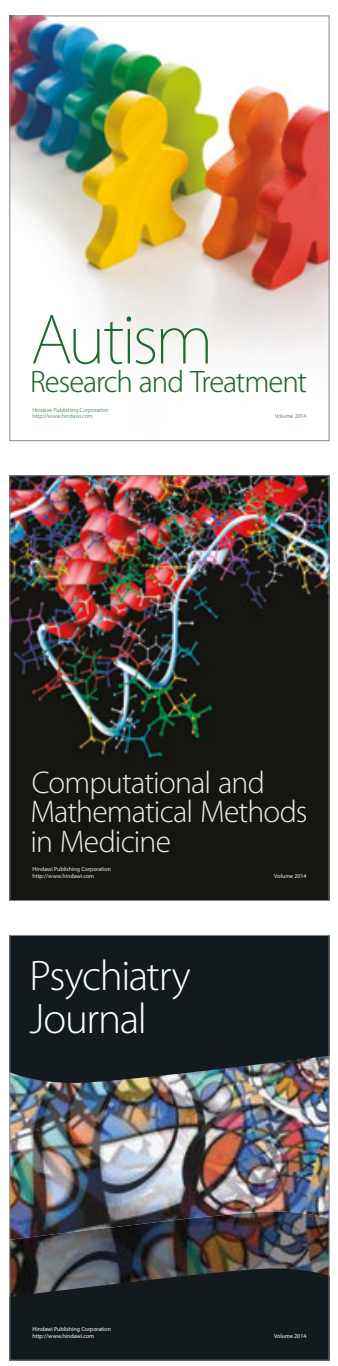
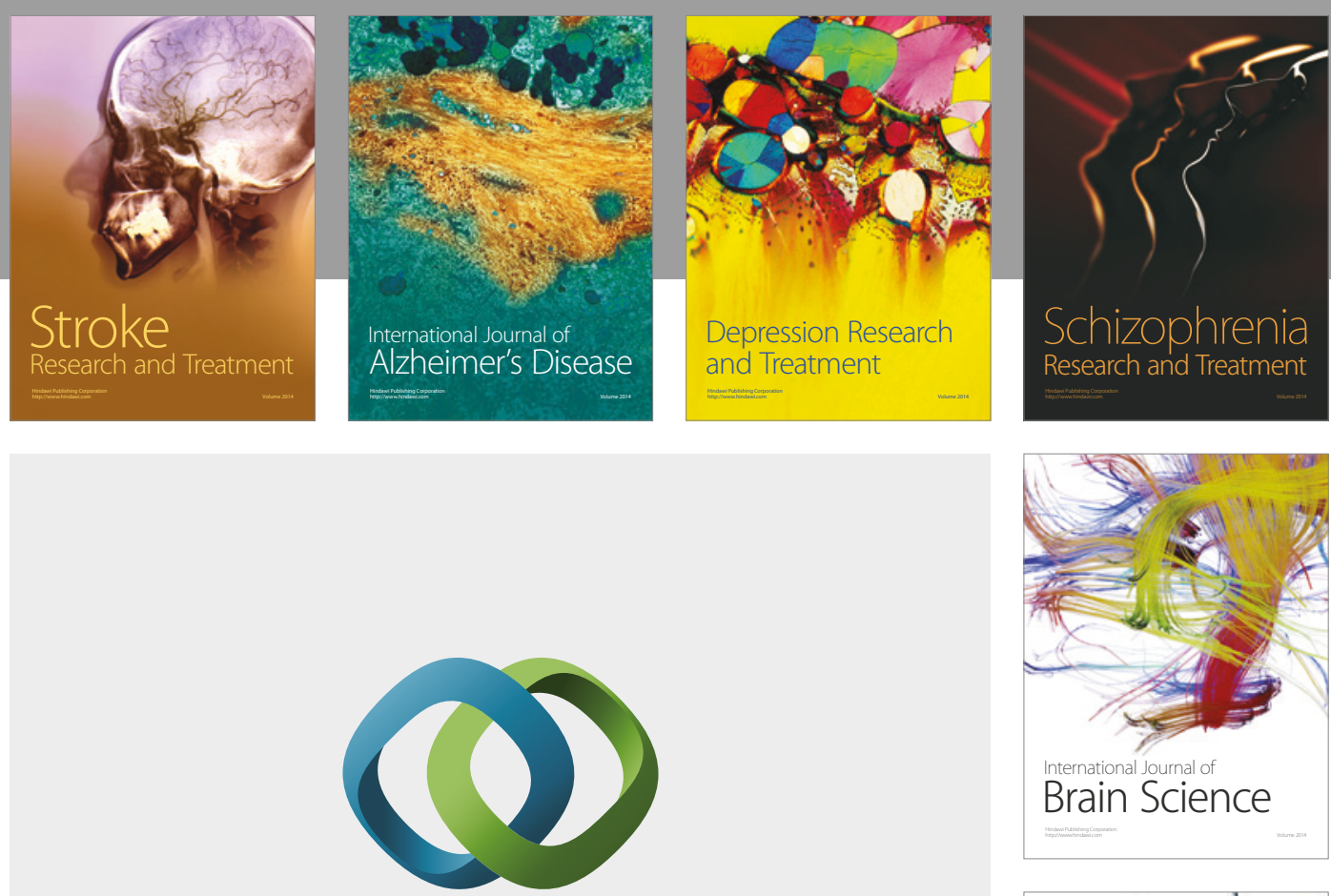

\section{Hindawi}

Submit your manuscripts at

https://www.hindawi.com
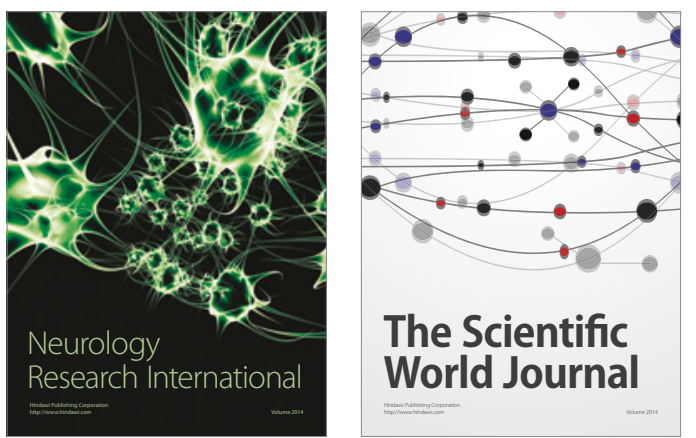

The Scientific World Journal

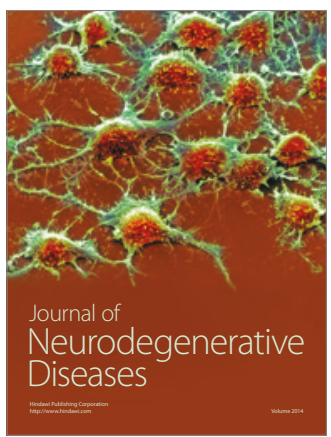

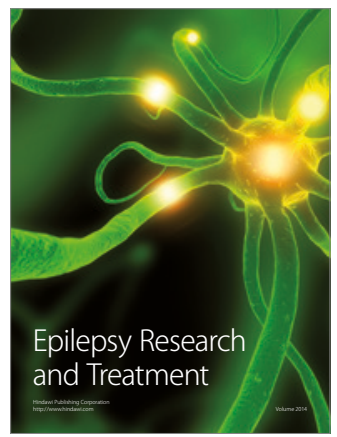

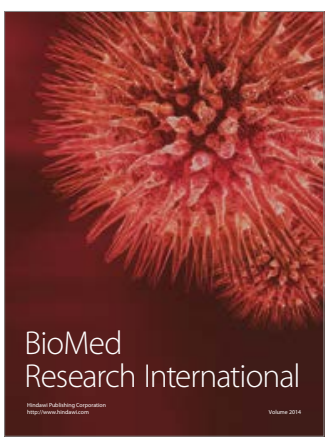

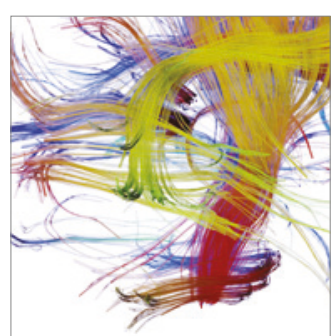

Brain Science

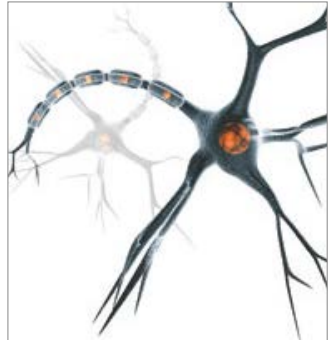

Neural Plasticity
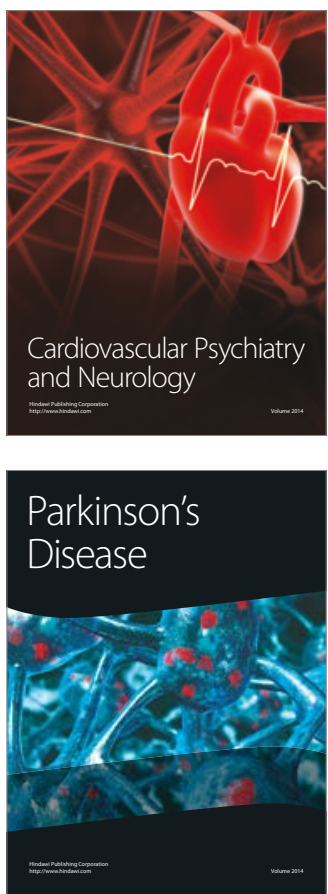